\title{
Traveling waves in developing cerebellar cortex mediated by asymmetrical Purkinje cell connectivity
}

\author{
Alanna J. Watt ${ }^{1}$, Hermann Cuntz ${ }^{1}$, Masahiro Mori ${ }^{1}{ }^{1}$, Zoltan Nusser $^{3}$, P. Jesper Sjöström ${ }^{1}$, \\ and Michael Häusser ${ }^{1}$ \\ ${ }^{1}$ Wolfson Institute for Biomedical Research and Department of Neuroscience, Physiology, and \\ Pharmacology, University College London, Gower Street, London WC1E 6BT, UK \\ ${ }^{2}$ Department of Physiology and Biological Information, Dokkyo Medical University, 880 \\ Kitakobayashi Mibu-machi, Shimotsuga-gun, Tochigi 321-029, Japan \\ ${ }^{3}$ Laboratory of Cellular Neurophysiology, Institute of Experimental Medicine, Hungarian Academy \\ of Sciences, 1083 Budapest, Hungary
}

\begin{abstract}
Correlated network activity plays a critical role in the development of many neural circuits. Purkinje cells are among the first neurons to populate the cerebellar cortex, where they sprout exuberant axon collaterals. Here we use multiple patch-clamp recordings targeted with two-photon microscopy to characterize monosynaptic connections between Purkinje cells of juvenile mice. We show that Purkinje cell axon collaterals project asymmetrically in the sagittal plane, directed away from the lobule apex. Based on our anatomical and physiological characterization of this connection, we construct a network model that robustly generates waves of activity traveling along chains of connected Purkinje cells. Consistent with the model, we observe traveling waves of activity in Purkinje cells in sagittal slices from young mice that require $\mathrm{GABA}_{\mathrm{A}}$ receptormediated transmission and intact Purkinje cell axon collaterals. These traveling waves are absent in adult animals, suggesting they play a developmental role in wiring the cerebellar cortical microcircuit.
\end{abstract}

\section{Introduction}

The cerebellar cortex is one of the best-characterized circuits of the central nervous system and is known to play a key role in the precise timing of motor control1. Purkinje cells form the sole output of the cerebellar cortex and project to the deep nuclei of the cerebellum (DCN) where they form GABAergic synapses. Purkinje cells also exhibit local axon collaterals, which typically bifurcate in the granule cell layer and project back up to the Purkinje cell layer, and occasionally into the molecular layer2. The synaptic target(s) and function of the Purkinje cell local axon collaterals have long been the subject of controversy, although since the pioneering work of Cajal some studies suggested that they form synapses onto other Purkinje cells2-4 (but see Refs. ${ }^{5},{ }^{6}$ ). Direct evidence for functional synaptic connections between Purkinje cells has only recently been described7. Since this local recurrent pathway is generated by the output neurons of the network, it is poised to play an important role in controlling activity patterns of the cerebellar cortex. Indeed, a recent modeling study suggested that Purkinje-Purkinje connections could both enhance temporal integration and synchronize neurons in the cerebellar cortex8.

Address for correspondence: Alanna J. Watt, Wolfson Institute for Biomedical Research, University College London, Gower Street, London WC1E 6BT, UK, Tel. +44-(0)20-7679-6777, Fax +44-(0)20-7679-6878, Email: a.watt@ucl.ac.uk. 
Given that Purkinje cells are among the earliest neurons to migrate into the cerebellar cortex (as early as E15: Ref. ${ }^{9}$ ), they are in the right place at the right time to orchestrate the development of the synaptic connections in the cerebellar cortex. It has recently been demonstrated that the axon collaterals of Purkinje cells are particularly exuberant and are pruned to a mature distribution by the third week of postnatal development10. This suggests that Purkinje-Purkinje synapses may be particularly important during early stages of development, at a time when basket and stellate cell synaptic inputs onto Purkinje cells are not yet established11.

In several CNS regions, including the visual system, the hippocampus and the spinal cord, spontaneous traveling waves of activity early in development are critical in establishing the accurate synaptic connectivity of mature circuits12-14. However, wave-like activity has not previously been described in the developing cerebellum. To investigate the properties of monosynaptic connections between Purkinje cells and probe their contribution to network activity in cerebellar cortex, we have used two-photon laser scanning microscopy to guide targeted patch-clamp recordings from connected pairs in slices from transgenic mice expressing GFP in Purkinje cells. Our results demonstrate that the asymmetrically projecting Purkinje-Purkinje synaptic connections provide a robust substrate for propagating waves of activity in the developing (but not the adult) cerebellum.

\section{Results}

\section{Functional synapses between juvenile Purkinje cells}

To study the synaptic targets of Purkinje cell axon collaterals, we used transgenic mice expressing the fusion protein tau-GFP under the control of the Purkinje cell-specific L7 promoter15. In these mice, the tau component of the chimera results in GFP enrichment in axons15. Because the L7 promoter specifically drives expression in Purkinje cells, we could use GFP as a marker for Purkinje cell axon collaterals. To maximize the chance of obtaining synaptically connected pairs, we made targeted patch-clamp recordings from putatively connected pairs visualized using a custom-designed two-photon laser-scanning microscope in juvenile slices from L7-tau-GFP transgenic mice (or, in a few cases, GAD65-GFP mice16, 17). We visualized individual Purkinje cell axon collaterals and traced them to their putative postsynaptic targets (Fig. 1a, top; see Methods), which were also visualized using laser-scanning Dodt contrast imaging. We then made simultaneous triple or quadruple whole-cell recordings from candidate pre- and postsynaptic neurons. To confirm the identity of the neurons (cf. Fig. 1a, bottom), Alexa 594 and biocytin were included in the internal solution, permitting the imaging and subsequent reconstruction of the neurons (see below). Purkinje cells were hyperpolarized with constant DC current injection (presynaptic $\mathrm{V}_{\mathrm{m}}=$ $-69.1 \mathrm{mV} \pm 2.1 \mathrm{mV}$; postsynaptic $\mathrm{V}_{\mathrm{m}}=-74.6 \mathrm{mV} \pm 2.3 \mathrm{mV}, \mathrm{n}=20$ ) to prevent spontaneous spiking, and brief current pulses were injected to elicit spikes to test for connections. Synaptic connections between pairs of Purkinje cells were observed in $26 \%$ of attempts (or 23 pairs in 88 tested, P4 - P14). This was a 20 -fold improvement on the nontargeted connectivity rate, which was $1.3 \%$ (2 pairs out of 154 tested).

The Purkinje-Purkinje cell synaptic connections (Fig. 1b) were depolarizing in our recordings because of the symmetrical chloride internal solution, used to maximize synaptic driving force and thus the signal-to-noise ratio. The postsynaptic responses had short latencies and little temporal jitter (Fig. 1b, bottom; latency $=0.60 \pm 0.05 \mathrm{~ms}, \mathrm{n}=20$; Table 1 ), consistent with monosynaptic connections. The mean PSP rise time was $2.2 \pm 0.24 \mathrm{~ms}$ (n $=20)$, with a $\tau_{\text {decay }}$ of $20 \pm 1.9 \mathrm{~ms}(\mathrm{n}=17$; Table 1$)$. The mean peak amplitude of connected pairs was $1.9 \pm 0.63 \mathrm{mV}(\mathrm{n}=14$; Table 1 ; including failures), with a high degree of variability across connections (Table 1). The trial-to-trial variability in PSP amplitude was also considerable, with a coefficient of variation (CV: s.d. divided by the mean) of $0.9 \pm$ 
$0.13(\mathrm{n}=20$; Table 1). Consistent with the large range of CVs, failure rates were also variable (Table 1). Synaptic currents measured in voltage clamp exhibited relatively rapid kinetics (rise time $=0.8 \pm 0.13 \mathrm{~ms} ; \tau_{\text {decay }}=5.8 \pm 0.99 \mathrm{~ms} ; \mathrm{n}=11$; Table 1 ), consistent with a perisomatic location of the synaptic contacts as suggested by our light microscopic (LM) and electron microscopic (EM) immunohistochemical results (Fig. 2) and confirmed anatomically in reconstructions of connected pairs (Fig. 3c). Although the Purkinje-Purkinje synaptic properties were characterized over an age range during which the cerebellar circuit changes dramatically (P4 - P14), no significant differences in most synaptic properties were observed when comparing data from animals in P4 - P6 and P7 - P14 groups, allowing us to pool these data (see Supplementary Fig. 1). We applied the selective $\mathrm{GABA}_{\mathrm{A}}$ receptor antagonist SR95531 to investigate the receptors underlying the synaptic connection between Purkinje cells. SR95531 completely and reversibly abolished synaptic responses (Fig 1c), indicating that these synapses are GABAergic.

We next investigated the short-term plasticity of the Purkinje-Purkinje cell synapses with presynaptic spike trains and measuring the paired-pulse ratio of the responses (PPR, see Methods; Fig. 1d, e, f). Paired-pulse depression was observed at frequencies above $10 \mathrm{~Hz}$ (Fig. 1f), with increasing depression at higher frequencies, reaching a plateau of $\sim 40 \%$ at $\sim 90 \mathrm{~Hz}$. Paired-pulse depression was developmentally regulated: it was strong in the first postnatal week $(\mathrm{P} 4-\mathrm{P} 6$; PPR $=0.49 \pm 0.06)$ and significantly reduced in the second week (P7 - P14; $0.97 \pm 0.15 ; \mathrm{P}=0.009$; see Supplementary Fig. 1). In summary, synaptic connections between young Purkinje cells are GABAergic and exhibit short-term synaptic depression as well as high trial-to-trial and cell-to-cell variability in the amplitude and reliability of the response.

\section{Ultrastructure of synapses between Purkinje cells}

We further studied the distribution of synaptic contacts between Purkinje cells using immunolabeling at both LM and EM levels. Confocal imaging (Fig. 2a) showed Purkinje cell axons form presynaptic varicosities that were often directly apposed to Purkinje cell somata (Fig. 2a-d). To confirm that these varicosities were axon terminals containing vesicles, we performed double immunolabeling for vesicular inhibitory amino acid transporter (VIAAT) and GFP (Fig. 2e). These two markers showed a colocalization in many varicosities that were seemingly in direct contact with Purkinje cell somata (Fig. 2e; yellow $=$ red, VIAAT + green, GFP).

To investigate further, we examined these varicosities at the ultrastructural level by performing EM immunogold labeling against GFP. Our EM analysis confirmed the existence of symmetrical synaptic junctions made by GFP-positive axon terminals onto GFP-positive somata (Fig. 2f) and axon initial segments (ais; Fig. 2g, h). We also found perisomatic synaptic junctions that were made by immunonegative axon terminals (Fig. 2i), probably originating from basket cells that are beginning to innervate Purkinje cells at P8 (Ref. ${ }^{11}$ ). Taken together, our results demonstrate the existence of perisomatically located Purkinje-Purkinje cell synapses in juvenile cerebellum.

\section{Anatomical organization of Purkinje-Purkinje pathway}

To help determine the impact of the Purkinje-Purkinje connection on the cerebellar cortical network, we examined the anatomical organization of Purkinje cell collaterals following the reconstruction of the axons of biocytin-filled Purkinje cells. The main axon of Purkinje cells runs in the sagittal plane, projecting away from the tip (or apex) of a cerebellar lobule along the white matter towards the DCN3. Although there was considerable heterogeneity in the projection pattern of individual Purkinje cell axon collaterals (cf. Fig. 3a, c), when a large number of collaterals were examined, a motif emerged. We found a peak density of 
collaterals (and thus of postsynaptic partners) centered $\sim 60 \mu \mathrm{m}$ basally from the parent Purkinje cell, corresponding to $\sim 1-5$ Purkinje cell bodies (Fig. 3b). This argues that Purkinje-Purkinje cell connections are not randomly distributed in the cerebellar cortex, but instead form directed chains of connected cells in the sagittal plane. These chains begin at the apex of the cerebellar lobules and project basally (see Supplementary Movie 1). Since these data were obtained from cells lying at different locations in many lobules within the cerebellar vermis (Supplementary Fig. 2), we suggest this asymmetry may be a general feature of Purkinje axon collaterals. The anatomical asymmetry was confirmed in our functional connectivity data: in 20 out of 23 connected pairs (87\%), the postsynaptic Purkinje cell was further away from the apex of the lobule than the presynaptic cell. Additionally, although we always tested for reciprocal connections, they were never observed.

We could visually identify sites of putative synaptic contact at the LM level in a subset of connected pairs $(n=7)$ that were digitally reconstructed. In most pairs, the presynaptic axon collateral branched significantly in the upper granule cell layer and Purkinje cell layer, and then appeared to contact the postsynaptic Purkinje cell with several axon collaterals (cf. Fig $3 c)$. In the majority of reconstructed pairs, the presynaptic axon collateral remained within the Purkinje cell layer without extending appreciably into the molecular layer, which implies that most synaptic contacts were not on dendrites. However, the occasional Purkinje cell collateral did enter the molecular layer (cf. Fig. 2a, 3b). On average, there were $3.7 \pm 0.8$ putative synaptic contacts made between each connected Purkinje cell pair (Table 1; $\mathrm{n}=7$ reconstructed pairs). Of these contacts, $\sim 90 \%$ were made onto the soma and the remaining $\sim 10 \%$ onto the ais (Fig. 3c, inset), consistent with the EM localization of Purkinje-Purkinje cell synapses (cf. Fig. 2g, h).

\section{Entrainment of spiking by Purkinje-Purkinje synapses}

Cerebellar Purkinje cells intrinsically generate regular spontaneous firing in the absence of synaptic input 18,19 . The impact of a synaptic input to a Purkinje cell can thus be measured by the extent to which it shifts the phase of spiking20, rather than by the resulting membrane potential deflection at the soma. To assess the influence of Purkinje-Purkinje cell synaptic connections on Purkinje cell spiking, we used dynamic-clamp circuitry to inject a conductance that mimicked this synaptic connection while allowing the "postsynaptic" cell to spike freely. Conductance kinetics and amplitude were based on our paired recording data (Table 1, and Supplementary Methods). Since the GABAergic reversal potential changes with development over the age range that we have studied (Supplementary Fig. 1, and Ref. ${ }^{21}$ ), we therefore additionally benefited from the use of dynamic clamp, as it allowed us to vary the synaptic reversal potential while investigating the impact on postsynaptic spiking in the same Purkinje cell. Since Purkinje-Purkinje synapses were located primarily perisomatically (Fig. 3c, Fig. 2g, h), dynamic clamp with a somatic pipette accurately simulated this synaptic input (Fig. 4a).

When we injected a simulated depolarizing synaptic conductance in a freely spiking neuron (Fig. 4b, red traces), a structured firing pattern emerged in the postsynaptic cell. A similar but opposite effect was seen when the synaptic conductance was hyperpolarizing (Fig. 4c, blue traces). As shown by cross-correlograms between spiking in the mock presynaptic neuron and the postsynaptic neuron, for depolarizing (Fig. 4b, inset right) and hyperpolarizing reversal potentials (Fig. 4c, inset right), the simulated Purkinje cell connection entrained the postsynaptic cell.

We quantified the degree and the phase of entrainment by fitting sine waves to the crosscorrelograms of pre- and postsynaptic spiking: the degree of entrainment is reflected by the sine wave amplitude and the phase $(\varphi)$ by the location of the sinusoid peak. The degree of 
entrainment was smallest for reversal potentials around $-50 \mathrm{mV}$, when inhibition is shunting (cf. Ref. ${ }^{22}$ ). Entrainment increased progressively in both directions from this point (Fig. $4 d$ ). The phase depended on the direction of the reversal potential deflection: depolarizing reversal potentials promoted relatively in-phase synchronization, whereas hyperpolarization favored anti-phase firing (Fig. 4e). Although the sign and magnitude of the change in average postsynaptic spiking frequency was determined by the reversal potential, the firing rate was overall only weakly affected by turning on the dynamic clamp synapse (data not shown: change in frequency in all cases $<1 \mathrm{~Hz}, \mathrm{cf} .{ }^{22}$ ). Taken together, these results suggest that Purkinje-Purkinje connections can promote synchronization of Purkinje cells, with the phase of entrainment being dependent on the driving force at GABAergic synapses. For a given sign, however, the phase of entrainment was independent of the actual value of $\mathrm{E}_{\mathrm{GABA}}$.

\section{Waves of activity in model Purkinje cell chains}

The ability of the Purkinje-Purkinje synapse to produce entrainment of Purkinje cell spiking in combination with the asymmetric nature of the connectivity, suggests that this synaptic connection may be involved in coordinating waves of activity in the Purkinje cell network. To investigate this possibility, we built a model network of 50 Purkinje cells including the known set of active conductances in Purkinje cells23. The neurons were connected in a chain-like manner, based on the directional asymmetry observed in our study (Fig. 3a, b); each neuron was connected with the following five neurons in the chain (Fig. 5a). Two synaptic reversal potentials were studied: one for depolarizing synapses $\left(\mathrm{E}_{\mathrm{GABA}}=-40 \mathrm{mV}\right.$ ) and one for hyperpolarizing synapses $\left(\mathrm{E}_{\mathrm{GABA}}=-80 \mathrm{mV}\right.$; see Supplementary Fig. 1). All other synaptic parameters were drawn from distributions matching those measured in the experiments (see Supplementary Methods).

The model network of connected Purkinje cells exhibited spontaneous propagation of waves of activity (Fig. 5b, c). When the connection was excitatory, the first cell in the network was leading, causing the waves to propagate from the tip of the lobule down into the cerebellum (Fig. 5b, raster plot and left inset for schematic illustration; also see Supplementary Movie S2). For the hyperpolarizing case, the last cell led the wave, which propagated from the interior of the cerebellum toward the apex of the lobule (Fig. 5c; Supplementary Movie S3). These computer simulations thus provide a proof-of-principle that the connection between Purkinje cells could be the substrate for propagating waves of activity along the sagittal plane in the cerebellum.

To quantify the propagation of the waves, we performed a two-dimensional Fourier transformation on Purkinje cell binary spike trains from the network model, resulting in an angular spectrum of the raster plot. This decomposed the network spike train into waves of a given direction and velocity, represented as one distinct point on the spatial vs. temporal frequency axis. The occurrence of waves in the Purkinje cell network model is validated by the peaks at either side of the $0 \mathrm{~mm}^{-1}$ spatial frequency line for the depolarizing and hyperpolarizing connections (Fig. 5e, f). The wave velocity of the wave was obtained from this; in these examples, the waves traveled at $\sim 30 \mathrm{~mm} / \mathrm{sec}$ for the depolarizing network and $\sim 2 \mathrm{~mm} / \mathrm{sec}$ for the hyperpolarizing network. When unconnected, the network of cells produced a band at the existing firing frequencies of the cells in the network without any distinct pattern on the spatial frequency axis (Fig. 5d). Note that in all cases, higher frequency harmonics were also visible. In addition to the angular spectrum decomposition approach described above, we calculated spike delay histograms to quantify the waves of activity that were generated by the network (Supplementary Fig. 4) which provided further verification of these traveling waves. 
Next, we assessed the robustness of the propagating waves, since they are unlikely to exist in the brain if they are not robust in the network model. The waves appeared across a wide range of parameter values (Supplementary Fig. 5, Methods), including halved synaptic strength, reduced number of postsynaptic partners, sparse connectivity, and increased firing rates. Changing the synaptic reversal potential to shunting inhibition, however, abolished the waves (Supplementary Fig. 5; cf. Ref. ${ }^{22}$ ). Although a switch from asymmetric to symmetric connectivity did not eliminate waves, it transformed them into standing waves of similar frequency (Supplementary Fig. 5). In summary, the traveling waves are a robust phenomenon and so are likely to be physiologically relevant.

\section{Traveling waves in juvenile sagittal cerebellar slices}

To test our model prediction that waves of activity travel across Purkinje cells arranged in the sagittal plane of lobules, we recorded from Purkinje cells in sagittal slices from young animals (P4 - P6). We monitored Purkinje cell firing patterns non-invasively with extracellular recording electrodes. Importantly, since basket and stellate cell inhibition is not yet established at this age 11, we could specifically isolate the effects of Purkinje cell synapses using $\mathrm{GABA}_{\mathrm{A}}$ receptor antagonists. Since $\mathrm{E}_{\mathrm{GABA}}$ we found that depolarizing at these ages (Supplementary Fig. 1), our model predicted that waves of activity would travel from the apex towards the base of a cerebellar lobule (cf. Fig. 5b, Supplementary Movie 2).

We used two-photon imaging to guide our electrodes to a region with intact axon collaterals and recorded activity from Purkinje cells lying within the same sagittal plane of the slice, typically 2-3 cell layers deep with a separation 50 to $350 \mu \mathrm{m}$. Simultaneous extracellular recordings were made from two or three Purkinje cells (Fig. 6 a, b). We looked for correlated activity between cells using a cross-correlation analysis of spike trains (Fig. 6b, left). Evidence for traveling waves of activity in Purkinje cells was determined by measuring the amplitude of a sine wave fit to the cross-correlogram; a bootstrap method was then employed to determine whether the cross-correlation was statistically significant (see

Supplementary Methods). Significant correlation was apparent in $40 \%$ of paired extracellular recordings ( 17 of 41 ). Considering that many of the axon collaterals are likely cut in the slice preparation, this $\sim 40 \%$ occurrence of waves probably represents a lower bound, so waves may be more prevalent in the intact brain. Importantly, even at this young age, the asymmetric projection of collaterals was present $(n=10$; data not shown). Similar to what has been observed early in other brain regions during early development 24 , cerebellar waves were intermittent, waxing and waning with time (see Supplementary Fig. $6)$.

To test whether the waves depend on GABAergic synapses (cf. Fig. 1c), we applied the selective $\mathrm{GABA}_{\mathrm{A}}$ receptor antagonist SR95531. Perfusion of SR95531 significantly reduced the occurrence of correlated activity from $\sim 40 \%$ in control conditions to $\sim 5 \%$ of paired recordings (Fig. 6b, c; 10 of 25 in controls; 1 of 15 during SR95531; $\mathrm{P}=0.012$ ), demonstrating that GABAergic synapses were critical for this form of correlated activity. Although Purkinje cell firing rates $(6.1 \pm 0.40 \mathrm{~Hz}, \mathrm{n}=48)$ were not altered by SR95531 $(5.43 \pm 0.40 \mathrm{~Hz}, \mathrm{n}=28 ; \mathrm{P}=0.48)$, one explanation for the absence of correlated firing in GABA blockade was that it arose indirectly due to an increase in the CV of firing in individual Purkinje cells during SR95531 application. However, GABA blockade did not significantly regularize firing at these ages $(C V=0.26 \pm 0.04$ control; $C V=0.35 \pm 0.05$ $\mathrm{SR} 95531 ; \mathrm{P}=0.12 ; \mathrm{n}=28$ ). In addition, although peaky cross-correlograms were absent in SR95531, auto-correlograms for both pre- and postsynaptic firing were indistinguishable following this treatment (Supplementary Fig. 6, and data not shown). These results demonstrate that the intrinsic firing of Purkinje cells was not altered by SR95531. We conclude that $\mathrm{GABA}_{\mathrm{A}}$ receptors play a pivotal role in the correlated firing of neighboring 
Purkinje cells. Given that SR95531 blocks traveling waves at a developmental time point when other inhibitory inputs are not yet established11, these results argue that the asymmetrically projecting connections between Purkinje cells are likely to be the key substrate for these waves.

We hypothesized that correlated firing between recorded cells arose because of waves of activity traveling along chains of Purkinje cells away from the apex of the lobule and towards its base. If this hypothesis was correct, the correlations between pairs of cells should depend on their spacing, since this would determine their relative position in the chain of connected Purkinje cells. To examine this possibility, we measured the phase difference, $\varphi$, between recorded cells (see Supplementary Methods), and plotted it as a function of the number of Purkinje cells separating the electrodes. This produced a linear relationship: the phase difference was smaller for nearby cells and larger for more distant cells (Fig. 6d; R = $0.82 ; P=0.0001$ ), as predicted by the model when waves traveled away from the lobule apex. Furthermore, we found that waves moved at a speed of roughly 40 Purkinje cells/ period, or $\sim 3 \mathrm{~mm} / \mathrm{s}$, which was within the predicted range of the model. This lent further weight to our argument that the correlated firing arose from the Purkinje-Purkinje pathway, since this speed of propagation directly depends on the anatomical spacing of connected nodes in the chain of Purkinje cells.

To provide additional confirmation that the traveling waves were mediated by Purkinje axon collateral synapses, we performed two-photon optical lesions of axon collaterals using a Ti:Sapphire laser25, 26, or in a subset of cases $(n=2)$ we lesioned with surgical scissors, providing an orthogonal approach to pharmacological blockade of the connection. To target the axon collateral connections, we took advantage of the laminar structure of the cerebellar cortex, and performed repeated scanning of the laser in a zone perpendicular to the Purkinje cell layer across visualized axon collaterals (Fig. 7b). This approach enabled us to locally sever the majority of Purkinje cell axon collaterals. The tissue around the optical lesion appeared healthy both during and after the procedure (examined afterwards for up to two hours). The morphology of Purkinje cells on either side of the lesion appeared normal (cf. Fig. 7a, b) and Purkinje cell firing rates were unaffected $(6.61 \pm 0.34 \mathrm{~Hz}$, before the optical lesion, $\mathrm{n}=34 ; 6.03 \pm 0.37 \mathrm{~Hz}$ after, $\mathrm{n}=36 ; \mathrm{P}=0.25$ ). The optical lesion, however, abolished traveling waves of activity in Purkinje cells across the lesion. In some cases, we were able to maintain continuous extracellular recordings from one to two Purkinje cells on either side of the lesion (Fig 7a, b). In control experiments, waves of activity were observed in $\sim 40 \%$ of recordings made in the same but unlesioned tissue ( 7 of 17 recordings). These were performed either before cutting (Fig. 7a) or "upstream" of the cut, on the side closest to the lobule apex. When the Purkinje cell axon collaterals were ablated, cross-correlations were observed in only 1 of 18 recordings, a significant reduction from control conditions (Fig. 7b, c; P = 0.0047). The occasional presence of correlated activity across an optical lesion was not surprising given that the full depth of the slice could not readily be cut with the laser. Given that optical lesioning abolished correlated activity between pairs of Purkinje cells spanning the lesion, but not between pairs of Purkinje cells located distal to the lesion, these data suggest that the ablated axon collaterals were the critical substrate for these traveling waves. Taken together, our data provide strong evidence in favor of the view that the Purkinje-Purkinje cell axon collateral pathway is the substrate for traveling waves of activity in chains of connected Purkinje cells in the juvenile cerebellar cortex.

\section{Traveling waves are ontogenetically transient}

Although some Purkinje cell axon collaterals are pruned during development, at least a subset of Purkinje cells retain some of their local axon collaterals10. We thus investigated whether traveling waves were still present in older animals. Since traveling waves depend 
critically on the asymmetrical projection pattern of Purkinje cell axon collaterals, we first asked whether this persists in older animals. Although subtle differences in the axonal projection pattern may emerge during development, the general asymmetrical projection motif found in juveniles (cf. Fig. 3b) was maintained in older animals (Fig. 8a; P17 - P24; n $=14$ ). This suggested that Purkinje cell axon collaterals might maintain their capacity to generate traveling waves in the mature brain.

We next asked whether Purkinje cell axon collaterals made monosynaptic connections with other Purkinje cells in older animals. To address this question, we first examined the target of these collaterals in P18 animals at both LM and EM levels. Surprisingly, confocal imaging showed that although Purkinje cell axon collaterals enter the Purkinje cell layer, they appeared very close to but not directly apposed to nearby Purkinje cell somata (Fig. 8b; cf. young animals, Fig. 2a - d). Instead, a small gap between the presynaptic bouton and Purkinje cell soma was discernable in most cases (Fig. 8b). Our results thus suggested that these collaterals no longer directly target Purkinje cells in older animals. To further address this possibility, we next examined the target of Purkinje cell axon collaterals at the ultrastructural level. To visualize Purkinje cell axon terminals, we performed immunogold reactions against GFP. Our EM analysis revealed that although Purkinje cell axon collaterals were found within few hundreds of nanometers from Purkinje cell somata (Fig. 8c), they did not form synapses on them. Between Purkinje cell axons and somata, we typically found thin layers of presumed glial membrane (Fig. 8c, left). In addition, we could not find any presynaptic specializations or postsynaptic densities at these appositions, thus suggesting the absence of functional Purkinje-Purkinje cell synapses. However, Purkinje cell axon terminals did form synapses onto nearby dendrites of unlabelled non-Purkinje cells (Fig. 8c), perhaps arising from basket cells27, which argues that the examined Purkinje cell axons were indeed fully functional and able to form synapses.

To investigate further the existence of monosynaptic Purkinje-Purkinje cell connections in relatively mature animals, we performed targeted paired recordings as described earlier. In agreement with our LM and EM results, we found no monosynaptically connected Purkinje cell pairs in three-week-old mice (Fig. 8d; P17 - P25: 0 pairs out of 25 tested, compared to $\mathrm{P} 4-\mathrm{P} 14,23$ pairs out of 88 tested; significantly different, $\mathrm{P}=0.002$ ). Although we cannot rule out the existence of sparse Purkinje-Purkinje synapses in older animals, our results suggest that the Purkinje-Purkinje pathway is pruned following postnatal development and that Purkinje cells are not the main target of Purkinje cell local axon collaterals in adult animals.

We next investigated whether traveling waves of activity exist in sagittal slices from older animals using the same methods employed in young animals. Although correlated activity was sometimes observed and at times appeared quite strong, bootstrap analysis showed that these correlations were usually not statistically significant but spurious, arising as a result of the much more regular firing and overall higher firing frequencies of mature Purkinje cells 28 , 29. Indeed, significantly correlated activity was rarely observed in older animals, and significantly less often than in young animals (Fig. 8e; young: 17 of 41 recordings; old: 5 of 81 ; $<$ 0.0001). Finally, the occasional incidence of correlated activity in mature cerebellar cortex was not significantly altered following the blockade of $\mathrm{GABA}_{\mathrm{A}}$ receptors (Fig. 8f, left; SR95531: 1 of 20 recordings; control: 3 of 34; P = 0.31), nor by optical lesioning of Purkinje cell axons (Fig. 8f, right; before lesion: 2 of 46 recordings; after: 3 of $32 ; \mathrm{P}=0.18$ ), again suggesting that the rare occurrence of cross-correlations in older animals was spurious in nature and not mediated by Purkinje axon signaling.

Taken together, our anatomical, electrophysiological, and modeling results suggest that Purkinje-Purkinje cell monosynaptic connections are the substrate of traveling waves in 
juvenile animals. The fact that we did not find direct monosynaptic connections or significant traveling waves in older animals adds weight to our conclusion that the PurkinjePurkinje pathway underpins these waves. Furthermore, the observation that these traveling waves are ontogenetically transient suggests that they may play a role in the development of the cerebellar circuit.

\section{Discussion}

We provide anatomical and physiological evidence that Purkinje cells are monosynaptically connected via GABAergic synapses in juvenile mice. These Purkinje-Purkinje synapses have a potent excitatory or inhibitory effect on postsynaptic spiking, depending on $\mathrm{E}_{\mathrm{GABA}}$ and developmental stage. The connection exhibits a marked asymmetry along the sagittal axis of a cerebellar folium. A realistic model based on the experimentally determined parameters demonstrates that this connection can mediate traveling waves of activity within the cerebellar cortex. We test this model and directly demonstrate for the first time the presence of waves of activity in juvenile sagittal cerebellum, and use pharmacological blockers and optical lesions to show that these waves arise predominantly from Purkinje cell local axon collaterals. These waves are ontogenetically transient, as they were not observed in more mature slices, where our anatomical and physiological results suggest that the majority of monosynaptic connections between Purkinje cells have been pruned. This is in agreement with some previous reports5, 6, although others have found evidence for Purkinje-Purkinje synapses in adults2, 4, although their criteria for identifying Purkinje cell axons are not as specific as the immuno-EM labeling that we use. Since the proper development of mature circuits in other juvenile brain regions is known to be critically dependent on early and ontogenetically transient wave activity $12-14$, we suggest that waves of activity traveling along chains of connected Purkinje cells in immature cerebellum may play a similar important role in cerebellar development.

\section{An asymmetric synaptic connection between Purkinje cells}

Our combined anatomical and physiological results indicate that the Purkinje-Purkinje synapses represent a significant feature of the connectivity of the developing cerebellar cortex. Nearly $1 / 3$ of pairs of neighboring Purkinje cells in the sagittal plane formed functional connections, revealed using targeted recordings. Purkinje cell collaterals can extend to over $200 \mu \mathrm{m}$ from the parent soma (Fig. 3b, and for e.g. Refs. ${ }^{2,} 27,30$ ), indicating that a single Purkinje cell could target as many as 10 neighboring Purkinje cells, though most of our functional connections were made within $100 \mu \mathrm{m}$ from the parent soma. The connectivity rate is developmentally regulated, it is highest in young animals, appears to decrease during the second postnatal week7, and by the third postnatal week, functional synaptic connections are very sparse or even absent (Fig. 8). This finding may explain why functional connectivity among Purkinje cells was not observed in many previous slice experiments.

We found that a defining feature of this synaptic connection is a striking asymmetry in the projection of the Purkinje cell axon collateral, which exhibits a strong preference to follow the direction of projection of the main axon in the sagittal plane. This is predominantly away from the apex of the folium and towards the white matter and the DCN at the center of the cerebellum. We did not observe reciprocal connections between Purkinje cells, in stark contrast to the neocortex, where circular and reciprocal connectivity motifs among neighboring pyramidal neurons are common31. This asymmetry should also hold for any functional connections made by the Purkinje cell collaterals with other potential targets in the cerebellar cortex, such as GABAergic interneurons27. It will be interesting to determine the molecular and cellular mechanisms which are responsible for establishing and maintaining this directionality, particularly since there is evidence for some pruning of axon 
collaterals during development10, and since the collaterals appear to respect the zebrin compartmentalization of the cerebellar cortex 30 .

\section{Strength and synaptic dynamics of the connection}

We demonstrate that the synaptic connection between Purkinje cells is mediated by activation of $\mathrm{GABA}_{\mathrm{A}}$ receptors, indicating that the same transmitter is released from the Purkinje cell collaterals as that released by synapses made by the main Purkinje cell axons in the DCN32, 33. Our dynamic clamp data indicates that unitary Purkinje-Purkinje synapses can have a significant effect on the spiking of postsynaptic Purkinje cells, either delaying or advancing spontaneous spikes, depending on the reversal potential. This is comparable to the effect of basket and stellate cell connections with Purkinje cells, where unitary inputs can also significantly inhibit Purkinje cell spiking19, 34. Given that basket and stellate cell inputs do not appear until the second postnatal week11, this indicates that the PurkinjePurkinje synapses may have a dominant effect on excitability in the first postnatal week, further ensured by the axosomatic location of their synaptic contacts. Interestingly, the basket/stellate cell connections with Purkinje cells undergo a dramatic 11-fold weakening during development (from P11 to P31; Ref. ${ }^{35}$ ). There does not seem to be a similar downregulation of cell mean synaptic conductance over the age range we have studied (see also Ref. ${ }^{7}$ ), although there appear to be a striking reduction in the connectivity rate, with the majority of Purkinje-Purkinje synapses being pruned by the third postnatal week (Fig. 8).

Early in development, the Purkinje-Purkinje cell synapse show robust short-term depression over a wide range of presynaptic firing rates. Following the second postnatal week, however, the synaptic dynamics eventually become facilitating (also see Ref. ${ }^{7}$ ). A similar change in synaptic dynamics during development has also been shown at other synaptic connections36, including at other inhibitory synapses onto Purkinje cells35. Since Purkinje cells are spontaneously active 18, 19 even at young ages, these synapses are likely to be tonically depressed over the normal range of Purkinje cell firing in vivo in young animals, in particular during the first postnatal week of development when the synaptic reversal potential is depolarizing and short-term depression is strongest (cf. Supplementary Fig. 1). This implies that, paradoxically, a pause in Purkinje cell spiking may release the synapse from this tonically depressed state ${ }^{32,33}$, producing an enhanced synaptic conductance. It will be of interest to determine which scenario predominates at these synapses at different stages of development in the juvenile cerebellar cortex.

\section{Traveling waves of activity in cerebellar cortex}

Although traveling waves of activity early in development are crucial for proper circuit development in several CNS regions12-14, this pattern of activity has to our knowledge not yet been described in the developing cerebellum. The mechanisms controlling early waves in other brain regions are diverse and can vary throughout development24. However, depolarizing GABAergic transmission early in development appears to be key in the production of waves in several circuits37, consistent with our findings in the cerebellum.

The cerebellar cortex has been thought to lack recurrent excitatory feedback, since the only intrinsic glutamatergic connections (made by granule cells and unipolar brush cells) are strictly feedforward. The discovery of functional connections between Purkinje cells, coupled with the demonstration that these connections can be excitatory early in development, provides a new pathway for recurrent local excitation. This pathway exhibits some striking differences from excitatory feedback connections in cortical circuits, which have been proposed to serve many functional roles, from gain control, signal restoration, input selection, information storage, and working memory through to their role in pathological states such as epilepsy38, 39. First, the excitation in the Purkinje cell recurrent 
network is ontogenetically transient as it switches to inhibition later in development, and is eventually pruned; second, the projection is directional: Purkinje cells tend to project in only one direction along the sagittal axis, and thus reciprocal connections are rare. Consequently, this connection is unlikely to sustain positive feedback and reverberant activity as in cortical circuits, since the network lacks the mutual reinforcement required for this to occur.

Our simple model of the Purkinje cell network, constrained by our functional and anatomical data, generates traveling waves of activity in the Purkinje cell population, the direction and speed of which depend on the GABAergic reversal potential. We directly validated our model by demonstrating the existence of traveling waves of activity in juvenile Purkinje cells in sagittal slices. Traveling waves have previously been shown to be an emergent property in network models (e.g. Ref. ${ }^{40}$ ). However, our model is the first to show waves of activity that rely on a known anatomical asymmetry in a single type of synaptic connection constrained directly by experimental data, and thus differ from previous models showing that Purkinje cell collaterals can promote synchrony in the form of standing waves, or oscillations in the Purkinje cell population8, 41. The anatomical origin of the waves (together with the kinetics of the synaptic connection and the spontaneous firing of the Purkinje cells) help to account for the different network dynamics in the Purkinje cell network compared to more conventional recurrent feedback-based excitatory and inhibitory network models, which exhibit synchrony but no clear waves ${ }^{22,42}$. It will be interesting to determine whether anatomical asymmetries in axonal projections found in other brain regions can also support waves, and also to determine to what extent waves documented experimentally in other brain areas (e.g. Ref. ${ }^{43}$ ) are linked to possible asymmetries in axonal projections.

\section{Functional implications of traveling waves}

What makes traveling waves different from other forms of oscillatory activity? Although theoretical and experimental evidence for oscillatory activity in the form of standing waves in the cerebellar cortex is abundant (for review, see Ref. ${ }^{44}$ ), our data represent to our knowledge the first evidence for traveling waves in the cerebellar cortex. Traveling waves are not incompatible with oscillatory activity in the form of standing waves. Indeed, traveling waves might appear as standing waves if the particular spatial properties of the wave are not captured in the recording configuration. It is also possible that both forms of activity may coexist, since both high-frequency standing wave oscillations and lowerfrequency traveling waves can arise from a population of spiking neurons. However, traveling waves are different from standing waves in that they propagate information across neuronal tissue; thus, the former contain directional information in addition to the temporal and spatial information that is contained in both types of waves. During development, traveling waves may therefore be poised to play a role in the formation of functional maps and local subnetworks. Indeed, a recent study in cat visual cortex 45 found that traveling waves were essential for a computational model to predict how synaptic plasticity rewires cortical maps after injury. In the same model, standing wave oscillatory activity, however, lead to incorrectly predicted remapping 45 . Recent work in the retina demonstrates that two temporally and mechanistically distinct forms of waves exist: early waves are standing whereas waves later in development are traveling. Furthermore, these later traveling waves are required to ensure the proper formation of the ON and OFF subnetworks in the retina46.

What is the functional role of these sagittal waves of activity in the developing Purkinje cell population? These waves could represent the sagittal counterpart to the activity patterns postulated to spread along the 'beam' of active parallel fibers47,48; the ordered propagation of the waves could provide a timing signal that is important for activating Purkinje cells associated with different components of a movement sequence. This in effect forms a novel functional compartment within the developing cerebellar cortex, whereby each lobule 
supports two traveling waves that move along opposite lobule banks (Fig. 9). One possibility is that the compartmentalization of the cerebellar cortex in the sagittal domain — which may include zebrin-expressing Purkinje cell clusters30 and the extent of sagittal spread of climbing fiber collaterals 49 - is partly governed by sagittal waves, together with appropriate activity-dependent synaptic plasticity learning rules.

Another possible and not mutually exclusive function of these early waves may be that they are involved in establishing the proper pattern of synaptic connectivity of Purkinje cell inputs to the DCN. Indeed, the impact of the waves of activity on the downstream neurons in the DCN will depend on the detailed pattern of synaptic connectivity, i.e. how the cerebellar folium is mapped onto individual DCN neurons, which is currently poorly understood. Should input from Purkinje cells along a folium be represented topographically in the DCN, these waves may play a role in the normal wiring of the DCN. Such a wiring strategy might permit directionally-dependent dendritic computation50, which would be sensitive to different directions of propagation of the waves in cerebellar cortex. In many brain regions, early spontaneous waves precede sensory input and are thought to provide a critical substrate in the organization of neuronal circuitry, which is further refined later in development by sensory input. We suggest that traveling waves could thus represent a cerebellar analog of these self-organizing, pre-sensory input circuit mechanisms. Further investigations of these waves are required to gain a better understanding of their functional roles during the development of the cerebellar circuit.

\section{Methods \\ Experiments}

All experiments were carried out in accordance with the animal care and handling guidelines approved by the U.K. Home Office. Acute cerebellar slices were prepared from P3 - P25 L7-tau-GFP mice15 (or in a few cases, from GAD65-GFP mice16, 17) using standard techniques19. All electrophysiological experiments were carried out at $33-35^{\circ} \mathrm{C}$. For confocal and electron microscopy, L7-tau-GFP mouse pups (P8 or P18) were transcardially perfused with fixative, and immunohistochemical and immmunogold labelling was performed. For further details see Supplementary Methods.

\section{Network modeling}

A network simulation consisting of 50 synaptically connected Purkinje cells was implemented in NEURON using a biophysical model of the Purkinje cell based on an existing model for spontaneously firing Purkinje cells23. The anatomical and physiological parameters of the model were tuned to replicate our experimental data. Further details are available in Supplementary Methods.

\section{Data analysis and statistics}

Data are reported as means \pm s.e.m. unless otherwise indicated. Data analysis was performed using Igor Pro and Matlab. Comparisons were made using either paired, two-tailed Student's t-tests or unpaired two-tailed Student's t-tests assuming unequal variances. Further details are available in Supplementary Methods.

\section{Supplementary Material}

Refer to Web version on PubMed Central for supplementary material. 


\section{Acknowledgments}

We thank Beverley Clark, Ian Duguid, Frances Edwards, Sarah Ho, Taro Ishikawa, Mickey London, Ede Rancz, Arnd Roth, and Spencer Smith, for helpful discussions and for comments on the manuscript. We are grateful to Sascha du Lac, Gábor Szabó and Ferenc Erdélyi for providing transgenic mice, to Jan Gruendemann for providing tissue for reconstructions, to Beverley Clark for help with perfusions, and to Latha Ramakrishnan and Kate Powell for expert assistance with histology and Neurolucida reconstructions. This work was funded by an EMBO LongTerm Fellowship and a Royal Society Dorothy Hodgkin Fellowship (A.J.W.); a Feodor Lynen Fellowship of the Alexander von Humboldt Foundation (H.C.); a European Young Investigator Award and a Wellcome Trust project grant (Z.N.); a Marie-Curie Intra-European fellowship and Medical Research Council Career Development Award (P.J.S.); a Wellcome Trust Senior Research Fellowship (M.H.); and a grant from the Gatsby Foundation (M.H.).

\section{References}

1. Ivry R. Cerebellar timing systems. Int Rev Neurobiol. 1997; 41:555-573. [PubMed: 9378608]

2. Chan-Palay V. The recurrent collaterals of Purkinje cell axons: a correlated study of the rat's cerebellar cortex with electron microscopy and the Golgi method. Z Anat Entwicklungsgesch. 1971; 134:200-234. [PubMed: 4326068]

3. Ramon, y; Cajal, S. Histologie du systeme nerveux de l'homme et des vertebres. Maloine; Paris: 1911.

4. Larramendi LM, Lemkey-Johnston N. The distribution of recurrent Purkinje collateral synapses in the mouse cerebellar cortex: an electron microscopic study. J Comp Neurol. 1970; 138:451-459. [PubMed: 5435296]

5. Hamori J, Szentagothai J. Identification of synapses formed in the cerebellar cortex by Purkinje axon collaterals: an electron microscope study. Exp Brain Res. 1968; 5:118-128. [PubMed: 5676978]

6. De Camilli P, Miller PE, Levitt P, Walter U, Greengard P. Anatomy of cerebellar Purkinje cells in the rat determined by a specific immunohistochemical marker. Neuroscience. 1984; 11:761-817. [PubMed: 6330609]

7. Orduz D, Llano I. Recurrent axon collaterals underlie facilitating synapses between cerebellar Purkinje cells. Proc Natl Acad Sci U S A. 2007; 104:17831-17836. [PubMed: 17965230]

8. Maex R, De Schutter E. Oscillations in the cerebellar cortex: a prediction of their frequency bands. Prog Brain Res. 2005; 148:181-188. [PubMed: 15661190]

9. Sotelo C. Cellular and genetic regulation of the development of the cerebellar system. Prog Neurobiol. 2004; 72:295-339. [PubMed: 15157725]

10. Gianola S, Savio T, Schwab ME, Rossi F. Cell-autonomous mechanisms and myelin-associated factors contribute to the development of Purkinje axon intracortical plexus in the rat cerebellum. J Neurosci. 2003; 23:4613-4624. [PubMed: 12805301]

11. Altman J. Postnatal development of the cerebellar cortex in the rat. II. Phases in the maturation of Purkinje cells and of the molecular layer. J Comp Neurol. 1972; 145:399-463. [PubMed: 5044254]

12. Feller MB. Spontaneous correlated activity in developing neural circuits. Neuron. 1999; 22:653656. [PubMed: 10230785]

13. Ben-Ari Y. Developing networks play a similar melody. Trends Neurosci. 2001; 24:353-360. [PubMed: 11356508]

14. Katz LC, Shatz CJ. Synaptic activity and the construction of cortical circuits. Science. 1996; 274:1133-1138. [PubMed: 8895456]

15. Sekirnjak C, Vissel B, Bollinger J, Faulstich M, du Lac S. Purkinje cell synapses target physiologically unique brainstem neurons. J Neurosci. 2003; 23:6392-6398. [PubMed: 12867525]

16. Bali B, Erdelyi F, Szabo G, Kovacs KJ. Visualization of stress-responsive inhibitory circuits in the GAD65-eGFP transgenic mice. Neurosci Lett. 2005; 380:60-65. [PubMed: 15854751]

17. Erdelyi, F., et al. GAD65-GFP Transgenic Mice Expressing GFP in the GABAergic Nervous System; FENS Meeting; Paris. 2003; A011.013

18. Raman IM, Bean BP. Resurgent sodium current and action potential formation in dissociated cerebellar Purkinje neurons. J Neurosci. 1997; 17:4517-4526. [PubMed: 9169512] 
19. Hausser M, Clark BA. Tonic synaptic inhibition modulates neuronal output pattern and spatiotemporal synaptic integration. Neuron. 1997; 19:665-678. [PubMed: 9331356]

20. Mittmann W, Hausser M. Linking synaptic plasticity and spike output at excitatory and inhibitory synapses onto cerebellar Purkinje cells. J Neurosci. 2007; 27:5559-5570. [PubMed: 17522301]

21. Eilers J, Plant TD, Marandi N, Konnerth A. GABA-mediated Ca2+ signalling in developing rat cerebellar Purkinje neurones. J Physiol. 2001; 536:429-437. [PubMed: 11600678]

22. Vida I, Bartos M, Jonas P. Shunting inhibition improves robustness of gamma oscillations in hippocampal interneuron networks by homogenizing firing rates. Neuron. 2006; 49:107-117. [PubMed: 16387643]

23. Khaliq ZM, Gouwens NW, Raman IM. The contribution of resurgent sodium current to highfrequency firing in Purkinje neurons: an experimental and modeling study. J Neurosci. 2003; 23:4899-4912. [PubMed: 12832512]

24. Firth SI, Wang CT, Feller MB. Retinal waves: mechanisms and function in visual system development. Cell Calcium. 2005; 37:425-432. [PubMed: 15820390]

25. Yanik MF, et al. Neurosurgery: functional regeneration after laser axotomy. Nature. 2004; 432:822. [PubMed: 15602545]

26. Mejia-Gervacio S, et al. Axonal speeding: shaping synaptic potentials in small neurons by the axonal membrane compartment. Neuron. 2007; 53:843-855. [PubMed: 17359919]

27. O'Donoghue DL, King JS, Bishop GA. Physiological and anatomical studies of the interactions between Purkinje cells and basket cells in the cat's cerebellar cortex: evidence for a unitary relationship. J Neurosci. 1989; 9:2141-2150. [PubMed: 2723768]

28. Brody CD. Correlations without synchrony. Neural Comput. 1999; 11:1537-1551. [PubMed: 10490937]

29. de la Rocha J, Doiron B, Shea-Brown E, Josic K, Reyes A. Correlation between neural spike trains increases with firing rate. Nature. 2007; 448:802-806. [PubMed: 17700699]

30. Hawkes R, Leclerc N. Purkinje cell axon collateral distributions reflect the chemical compartmentation of the rat cerebellar cortex. Brain Res. 1989; 476:279-290. [PubMed: 2702469]

31. Song S, Sjostrom PJ, Reigl M, Nelson S, Chklovskii DB. Highly nonrandom features of synaptic connectivity in local cortical circuits. PLoS Biol. 2005; 3:e68. [PubMed: 15737062]

32. Pedroarena CM, Schwarz C. Efficacy and short-term plasticity at GABAergic synapses between Purkinje and cerebellar nuclei neurons. J Neurophysiol. 2003; 89:704-715. [PubMed: 12574448]

33. Telgkamp P, Raman IM. Depression of inhibitory synaptic transmission between Purkinje cells and neurons of the cerebellar nuclei. J Neurosci. 2002; 22:8447-8457. [PubMed: 12351719]

34. Midtgaard J. Stellate cell inhibition of Purkinje cells in the turtle cerebellum in vitro. J Physiol. 1992; 457:355-367. [PubMed: 1297838]

35. Pouzat C, Hestrin S. Developmental regulation of basket/stellate cell-->Purkinje cell synapses in the cerebellum. J Neurosci. 1997; 17:9104-9112. [PubMed: 9364057]

36. Reyes A, Sakmann B. Developmental switch in the short-term modification of unitary EPSPs evoked in layer 2/3 and layer 5 pyramidal neurons of rat neocortex. J Neurosci. 1999; 19:38273835. [PubMed: 10234015]

37. Ben-Ari Y. Excitatory actions of gaba during development: the nature of the nurture. Nat Rev Neurosci. 2002; 3:728-739. [PubMed: 12209121]

38. Douglas RJ, Martin KA. Recurrent neuronal circuits in the neocortex. Curr Biol. 2007; 17:R496500. [PubMed: 17610826]

39. Connors BW, Telfeian AE. Dynamic properties of cells, synapses, circuits, and seizures in neocortex. Adv Neurol. 2000; 84:141-152. [PubMed: 11091864]

40. Cohen AH, et al. Modelling of intersegmental coordination in the lamprey central pattern generator for locomotion. Trends Neurosci. 1992; 15:434-438. [PubMed: 1281350]

41. de Solages C, et al. High-frequency organization and synchrony of activity in the purkinje cell layer of the cerebellum. Neuron. 2008; 58:775-788. [PubMed: 18549788]

42. Geisler C, Brunel N, Wang XJ. Contributions of intrinsic membrane dynamics to fast network oscillations with irregular neuronal discharges. J Neurophysiol. 2005; 94:4344-4361. [PubMed: 16093332] 
43. Lee SH, Blake R, Heeger DJ. Traveling waves of activity in primary visual cortex during binocular rivalry. Nat Neurosci. 2005; 8:22-23. [PubMed: 15580269]

44. De Zeeuw CI, Hoebeek FE, Schonewille M. Causes and consequences of oscillations in the cerebellar cortex. Neuron. 2008; 58:655-658. [PubMed: 18549777]

45. Young JM, et al. Cortical reorganization consistent with spike timing-but not correlationdependent plasticity. Nat Neurosci. 2007; 10:887-895. [PubMed: 17529985]

46. Kerschensteiner D, Wong RO. A precisely timed asynchronous pattern of ON and OFF retinal ganglion cell activity during propagation of retinal waves. Neuron. 2008; 58:851-858. [PubMed: 18579076]

47. Braitenberg V. Functional interpretation of cerebellar histology. Nature. 1961; 190:539-540.

48. Eccles, JC.; Szentagothai, J.; Ito, M. The Cerebellum as a Neuronal Machine. Springer-Verlag; Heidelberg: 1967.

49. Oberdick J, Baader SL, Schilling K. From zebra stripes to postal zones: deciphering patterns of gene expression in the cerebellum. Trends Neurosci. 1998; 21:383-390. [PubMed: 9735946]

50. Rall, W. Theoretical significance of dendritic trees for neuronal input-output relations. In: Reiss, R., editor. Neural Theory and Modeling. Stanford Univ. Press; Stanford, CA: 1964. p. 73-97. 

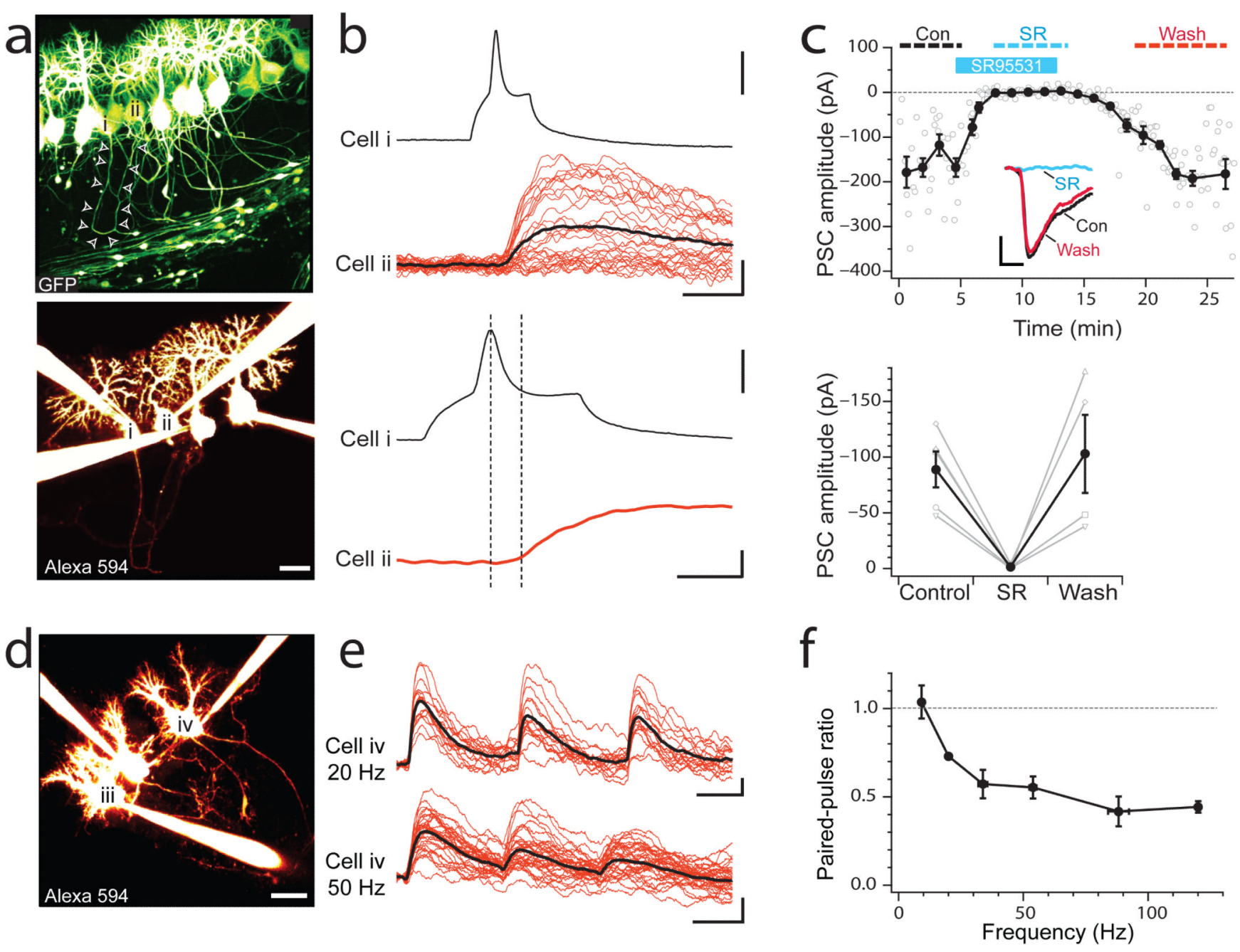

Figure 1. Unitary synaptic connections between neighboring Purkinje cells

(a) Top: Two-photon image of Purkinje cells from a P9 L7-tau-GFP mouse. Bottom: Quadruple whole-cell recordings of Purkinje cells selected from the GFP image above, imaged with Alexa 594 in the internal solution. A synaptic connection was found between cells (i) and (ii). Scale bar, $20 \mu \mathrm{m}$.

(b) Unitary synaptic connection between Purkinje cells. Upper panel: A spike in cell (i) evokes a PSP in cell (ii) (red: individual responses; black: average response; $\mathrm{V}_{\text {hold }}=-80$ $\mathrm{mV}$, with symmetrical chloride internal solution). Scale bar, $25 \mathrm{mV}$ (top), $2 \mathrm{mV}$ (bottom), 5 $\mathrm{ms}$. Lower panel: Same connection expanded to illustrate the latency. Scale bar, $25 \mathrm{mV}$ (top), $1 \mathrm{mV}$ (bottom), $2 \mathrm{~ms}$.

(c) Upper panel: Sample experiment showing synaptic currents were reversibly blocked by the $\mathrm{GABA}_{\mathrm{A}}$ receptor antagonist SR95531 $\left({ }^{\circ}=\right.$ individual responses; $\mathbf{O}=$ two-minute averages). Inset: Superimposed average PSCs (times indicated by the dashed lines). Scale bar, 50 pA, 4 ms. Lower panel: Summary data (grey symbols: individual experiments; black symbols: mean \pm s.e.m.; $n=5$ for control and $S R, n=4$ for wash).

(d) Recording configuration in (e). Cell (iii) was presynaptic to cell (iv). Scale bar, $20 \mu \mathrm{m}$.

(e) Responses in cell (iv) to $20 \mathrm{~Hz}$ (top) and $50 \mathrm{~Hz}$ (bottom) spike-trains in cell (iii) exhibited short-term depression (red: individual responses; black: averages). Scale bars, 0.5 ms, $20 \mathrm{~ms}$ (above), $0.5 \mathrm{~ms}, 10 \mathrm{~ms}$ (below). 
(f) Paired-pulse ratio (PPR) varies with presynaptic firing frequency (3 to 13 data points per bin; $\mathrm{n}=20$ connections). 

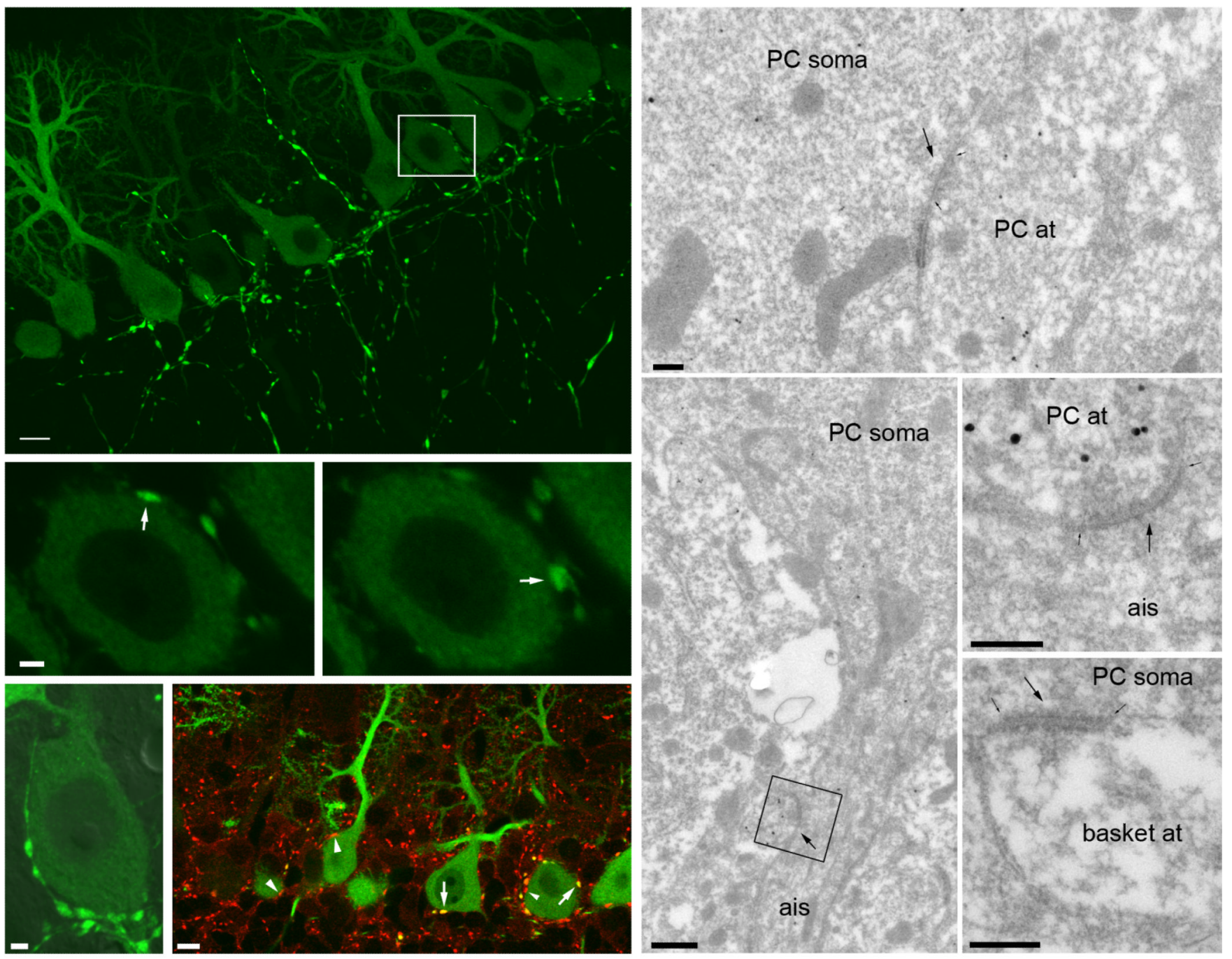

Figure 2. Purkinje cell local axon collaterals establish synapses on other Purkinje cells (a) Confocal laser scanning microscopic image of the cerebellar cortex of an L7-tau-GFP mouse. Scale bar, $10 \mu \mathrm{m}$.

(b, c) High magnification single optical section images from the area boxed in panel (a). Arrows indicate the site of potential synaptic interactions. Scale bar, $2 \mu \mathrm{m}$.

(d) A single Purkinje cell soma can be surrounded by a large number of Purkinje cell axon terminals. (fluorescent image is superimposed on a DIC image). Scale bar, $2 \mu \mathrm{m}$.

(e) Double immunofluorescent reaction for GFP (green) and vesicular inhibitory amino acid transporter (VIAAT, red) demonstrates that GFP containing Purkinje cell axon varicosities (arrows) are immunopositive for VIAAT (yellow). Some VIAAT immunopositive, but GFP negative boutons (arrowheads) also contact Purkinje cell somata. Scale bar, $5 \mu \mathrm{m}$.

(f) An electron micrograph showing a Purkinje cell axon terminal (PC at) establishing a synaptic junction (arrow) with a Purkinje cell soma. The presence of gold particles demonstrates immunoreactivity for GFP. Scale bar, $0.2 \mu \mathrm{m}$.

$(\mathbf{g}, \mathbf{h})$ An axon initial segment (ais) emerging from a Purkinje cell soma receives a synapse (arrow) from a GFP immunopositive axon terminal (PC at). Panel (h) shows the boxed area at a higher magnification. Scale bar, g: $0.5 \mu \mathrm{m} ; \mathbf{h}: 0.2 \mu \mathrm{m}$.

(i) Purkinje cell somata also receive synapses (arrow) from GFP immunonegative boutons, likely to be originating from basket cells (basket at). Scale bar, $0.2 \mu \mathrm{m}$. 

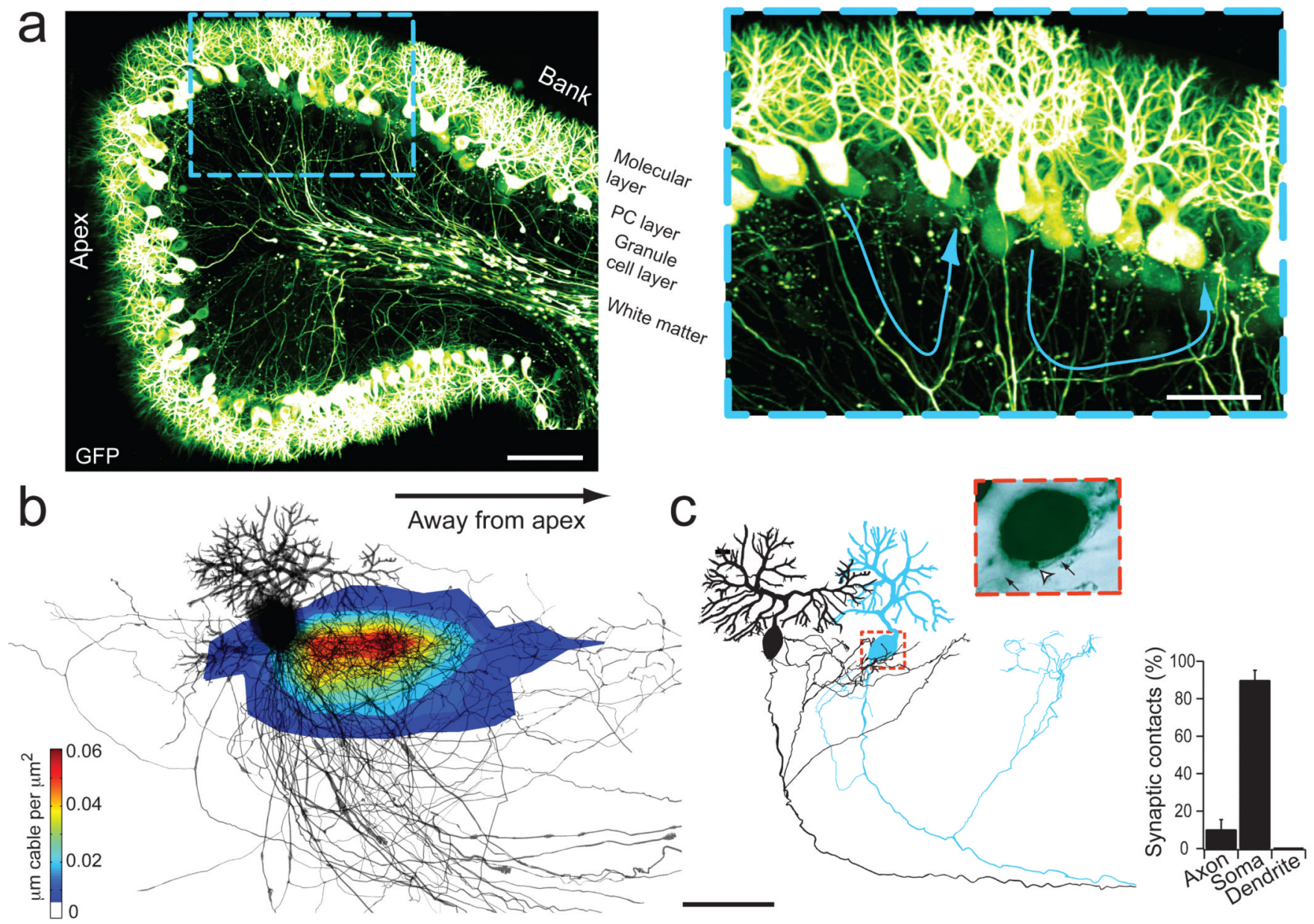

Figure 3. Anatomical distribution of Purkinje cell axon collaterals and Purkinje-Purkinje synapses

(a) Image of a lobule from a P9 mouse (left) and high-magnification image of the region indicated by the blue dashed box (right), with two axon collaterals highlighted with blue arrows. Scale bar, $100 \mu \mathrm{m}$; inset, $50 \mu \mathrm{m}$.

(b) Density plot of Purkinje cell axon collaterals. Purkinje cell somata and axons (and some dendrites) were reconstructed and superimposed $(n=39$; see Methods), oriented with their axons projecting away from the apex of the lobule (left) and towards the DCN (right), as indicated. The density of collaterals ( $\mu \mathrm{m}$ collateral cable per $\mu \mathrm{m}^{2}$ ) is shown using a colour scale, where red means highest and blue lowest density. Scale bar, $50 \mu \mathrm{m}$.

(c) Neurolucida reconstruction of connected Purkinje cells (presynaptic cell: black; postsynaptic cell: blue), and a corresponding LM single optical section (inset). The presynaptic axon (black arrows) made a putative presynaptic bouton onto the postsynaptic cell (white arrowhead). Summary of the subcellular location of putative synaptic contacts determined from biocytin-filled monosynaptically connected pairs is shown (bar graph, $\mathrm{n}=$ 7 pairs). Scale bar, $50 \mu \mathrm{m}$. 
a

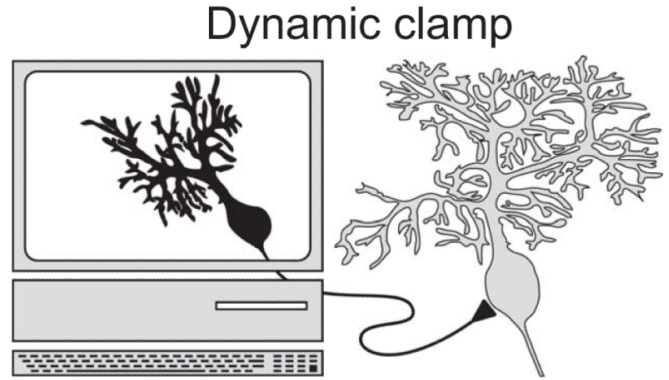

b
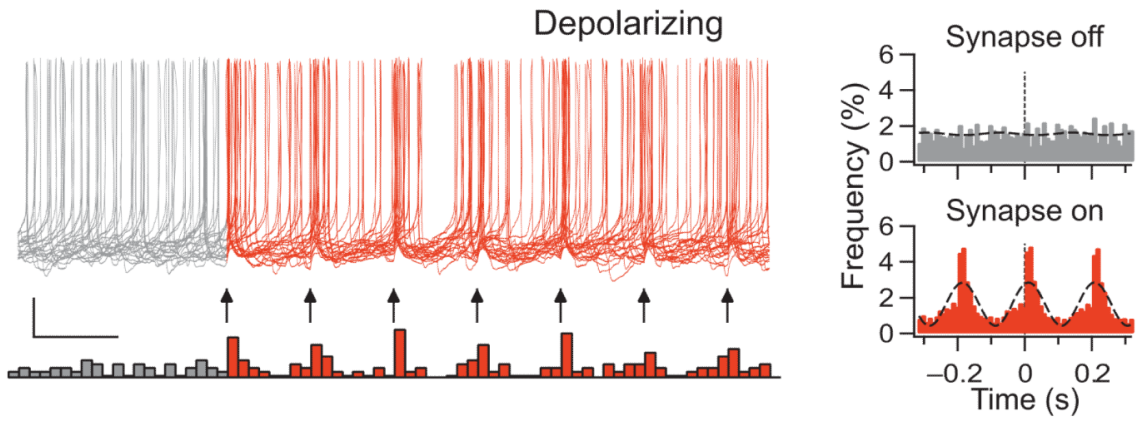

C
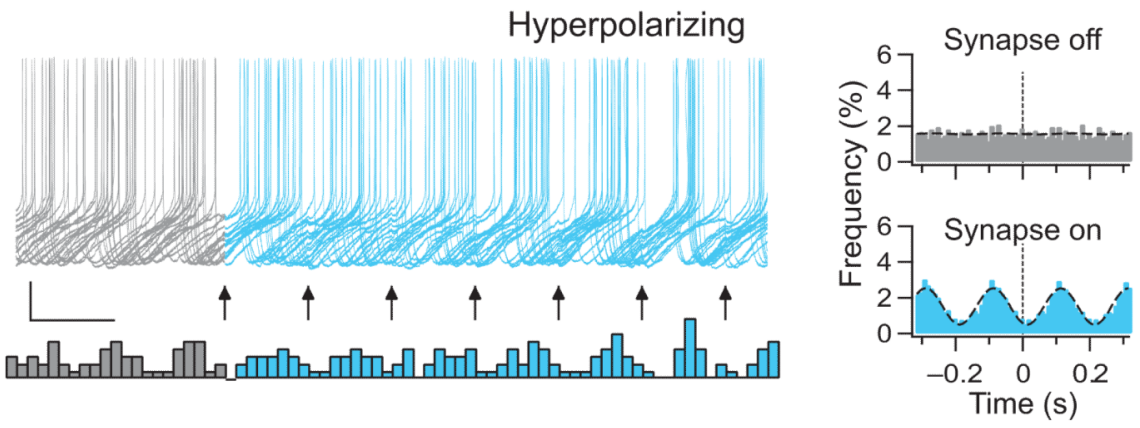

0
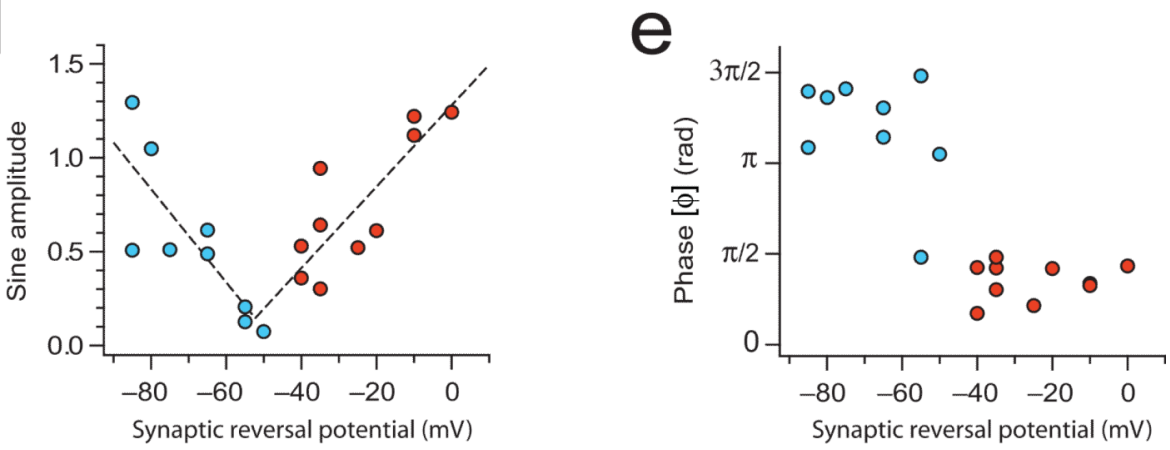

Figure 4. Purkinje cells synchronize in different phases depending on synaptic reversal potential (a) Schematic illustration of recording configuration where a computer-generated dynamic clamp synaptic conductance replaces the input from a presynaptic Purkinje cell.

(b) After a four-second-long baseline period (last $0.5 \mathrm{~s}$ shown; gray), a train of 40 dynamicclamp synaptic inputs ( $\mathrm{g}_{\mathrm{syn}}=1.5 \mathrm{nS} ; \mathrm{E}_{\mathrm{rev}}=0 \mathrm{mV}$; see Methods) were delivered at $5 \mathrm{~Hz}$ (first seven indicated by arrows), led to the emergence of correlated activity and Purkinje cell entrainment (top: 20 overlaid sweeps; bottom: spike histogram, spike rate: $5.8 \mathrm{~Hz}$; compare cross-correlograms inset right top and bottom). Scale bar, $10 \mathrm{mV}$ (above) or 10 APs (below), $200 \mathrm{~ms}$. 
(c) Switching on a similar but hyperpolarizing dynamic clamp synapse $\left(\mathrm{g}_{\mathrm{syn}}=1 \mathrm{nS} ; \mathrm{E}_{\mathrm{rev}}=\right.$ $-80 \mathrm{mV}$; see Methods) in another Purkinje cell also entrained structured spiking (top: 20 overlaid sweeps; bottom: spike histogram; rate: $5.4 \mathrm{~Hz}$ ) but with a different phase of the postsynaptic firing relative to the input (cf. cross-correlogram inset right bottom to that in b). Scale bar, $10 \mathrm{mV}$ (above) or 10 APs (below), $200 \mathrm{~ms}$.

(d) The amount of entrainment (cf. panels $\mathbf{b}, \mathbf{c}$ ) was greatest for strongly hyperpolarizing and strongly depolarizing synaptic reversal potentials (blue: $\mathrm{E}_{\text {rev }}<-50 \mathrm{mV}$; red: otherwise).

(e) The average phase $(\varphi)$ of the entrainment was significantly different for hyperpolarizing and depolarizing synaptic reversal potentials $(\mathrm{P}<0.001 ; \mathrm{n}=9$ for hyperpolarizing synaptic potentials and $\mathrm{n}=10$ for depolarizing). 


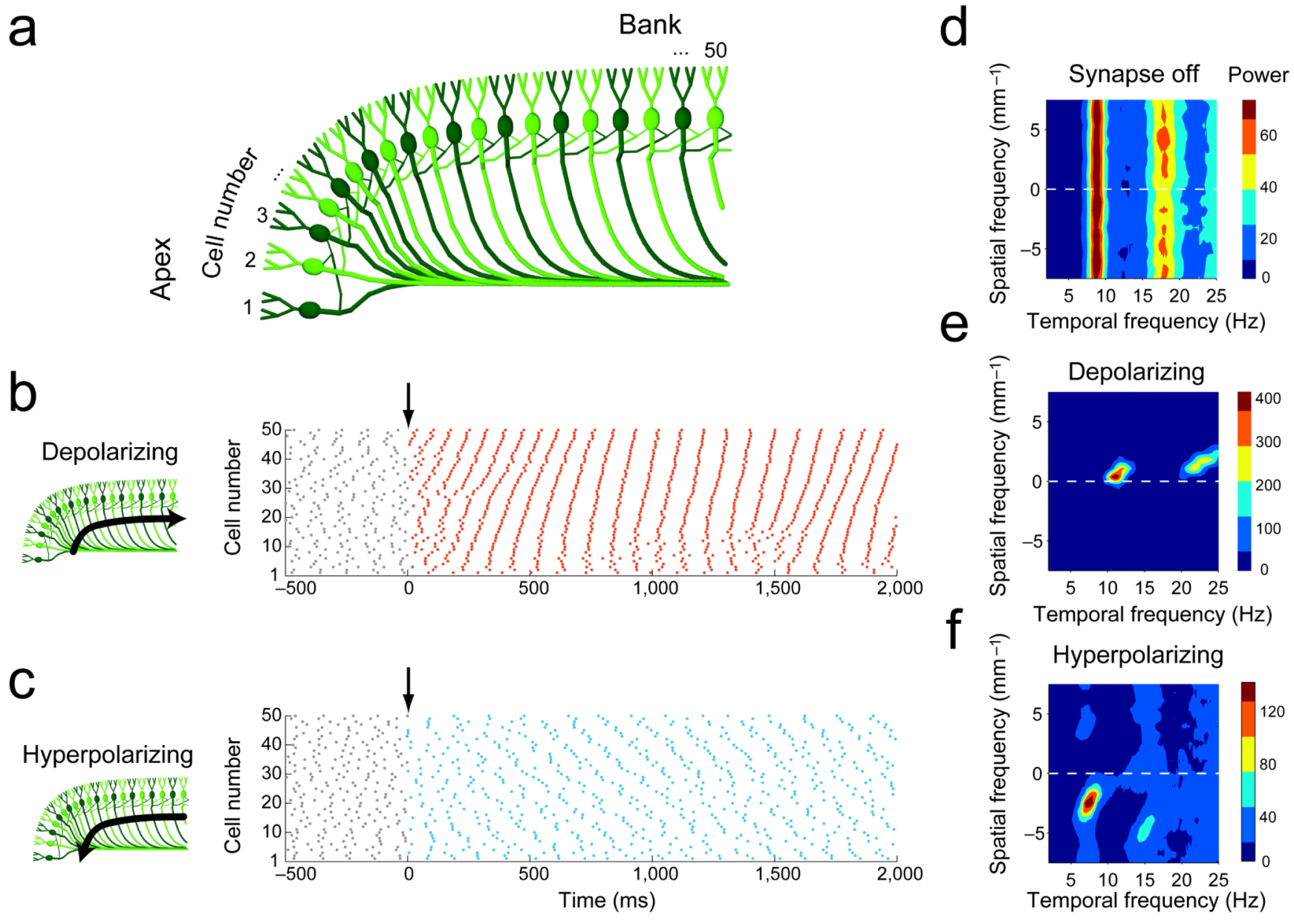

Figure 5. Waves of activity in a network model of Purkinje cells

(a) Schematic illustration of the Purkinje cell axon collateral network model (cells numbered starting at the apex of the folium). Each Purkinje cell was connected to the basally-located nearest neighboring five cells (for illustrative purposes, only two connections are shown, and cells have been colored in alternating colors).

(b) Raster plot from network model showing action potentials (individual dots) of Purkinje cells versus time (cells numbered as in (a)). Activation of depolarizing synapses (gray/red border, arrow) triggered waves of activity traveling from the apex to the base of the folium (black arrow).

(c) Activation of hyperpolarizing synapses (gray/blue border, arrow) triggered waves of activity traveling in the opposite direction (black arrow). Note that the connectivity of the two networks in (b) and (c) was identical; only $\mathrm{E}_{\mathrm{GABA}}$ differed.

(d - f) Two-dimensional Fourier transformation (2D FFT) contour plots corresponding to the angular spectrum of the raster plots. When the synapse was off (d), the 2D FFT exhibited a flat band in the temporal frequency without structure in the spatial frequency dimension. In contrast, the 2D FFT of the spike trains obtained with depolarizing (e) or hyperpolarizing connections (f) showed peaks corresponding to traveling waves. 


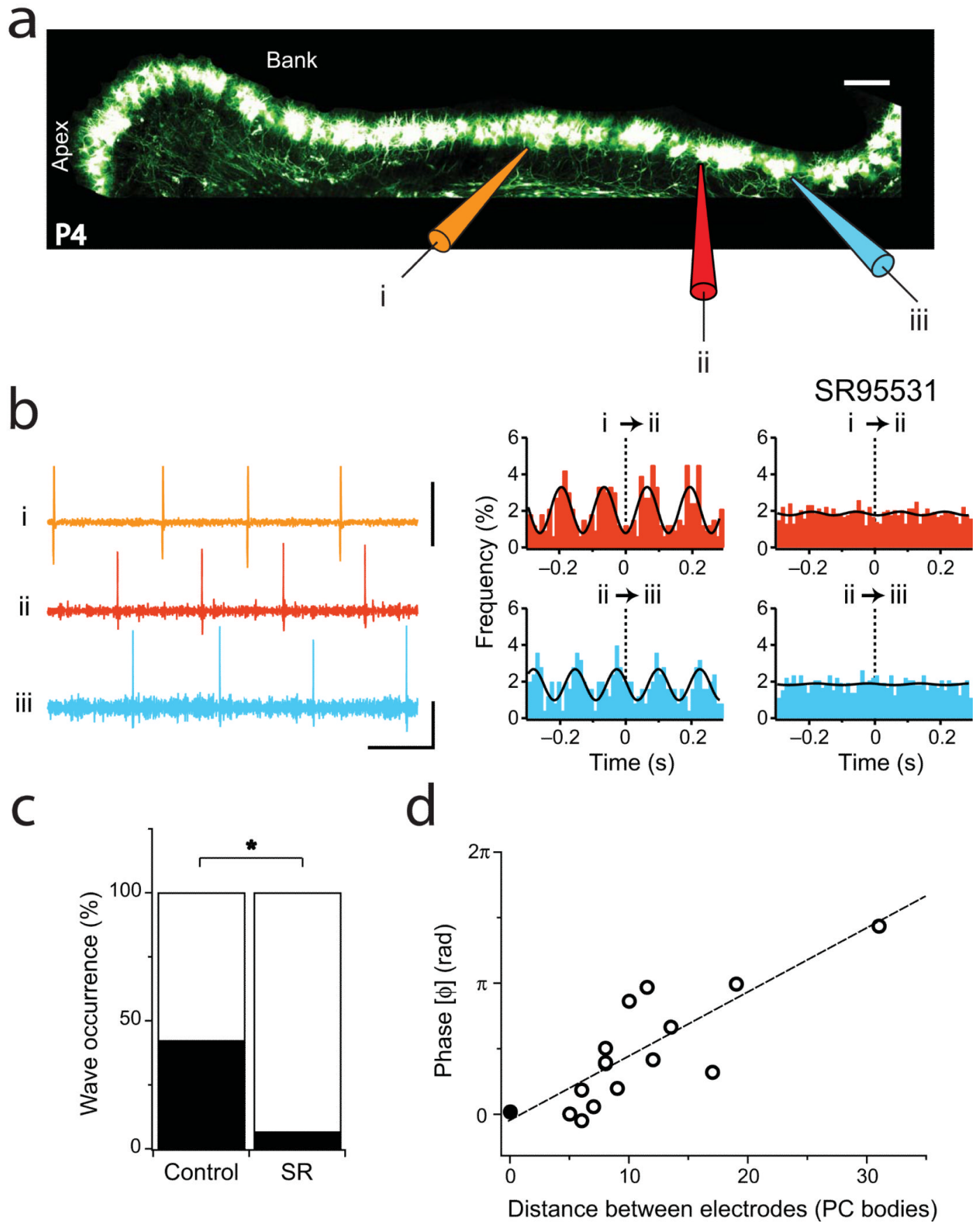

Figure 6. Traveling waves in sagittal cerebellar slices

(a) Cerebellar folium of a $\mathrm{P} 4$ L7-tau-GFP mouse illustrating the recording configuration in (b). Scale bar, $50 \mu \mathrm{m}$.

(b) Left: sample extracellular recording traces from electrodes in (a), showing waves of activity traveling away from the lobule apex. Scale bars, $1 \mathrm{nA}$ (top trace), $100 \mathrm{pA}$ (bottom two traces), $100 \mathrm{~ms}$. Right: Cross-correlograms for pairs i-ii and ii-iii indicate that firing is correlated. When the $\mathrm{GABA}_{\mathrm{A}}$ antagonist SR95531 is perfused, correlations are eliminated. (c) Summary data showing that the waves of activity observed in control conditions are abolished by SR95531. The perfusion of SR95531 (SR, right) significantly reduced the 
occurrence of wave-like activity between pairs of recordings from $\sim 40 \%$ to $\sim 5 \%$. (control waves: 10 out of 25 recordings, SR: 1 out of 15 recordings; * $\mathrm{P}=0.012$ ).

(d) Waves travel away from the lobule apex, since the phase $(\varphi)$ of the sinusoid fit to the cross-correlograms between cells is significantly correlated with the number of somata separating recorded cells and the slope is positive $(\mathrm{R}=0.81 ; \mathrm{P}=0.0001)$. Propagation velocity was $\sim 40$ Purkinje cells/period, or $\sim 3 \mathrm{~mm} / \mathrm{s}$. Closed circle at zero distance shows auto-correlogram data $(n=4)$. 

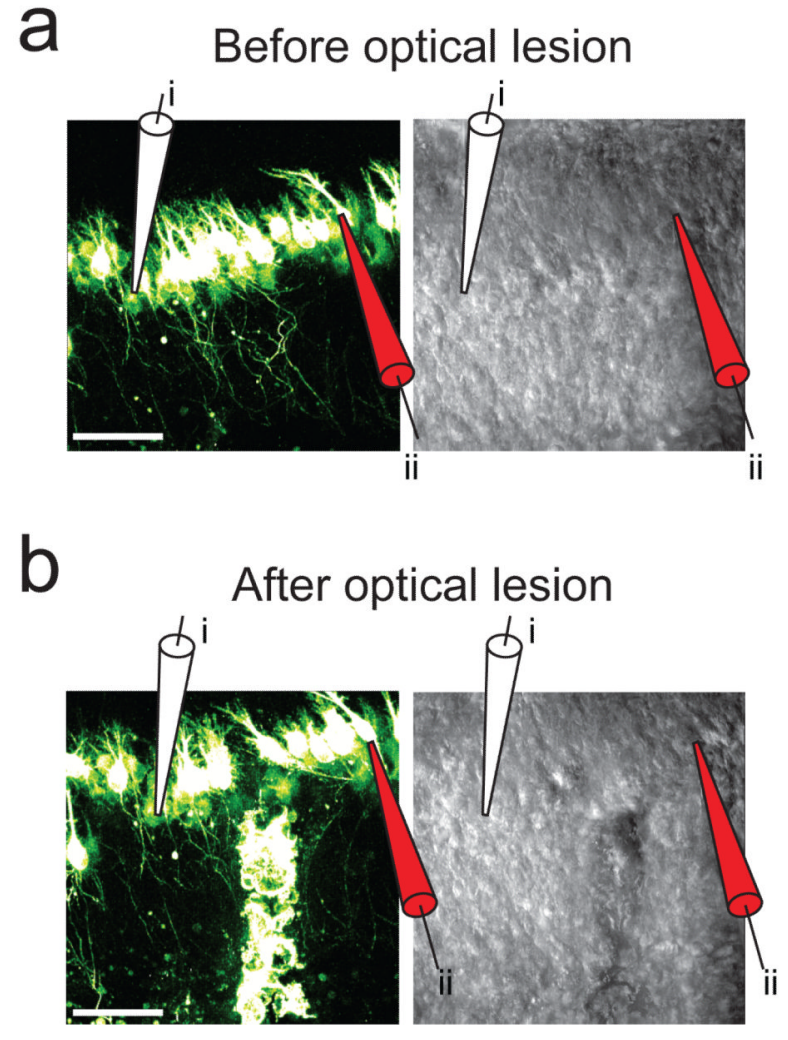
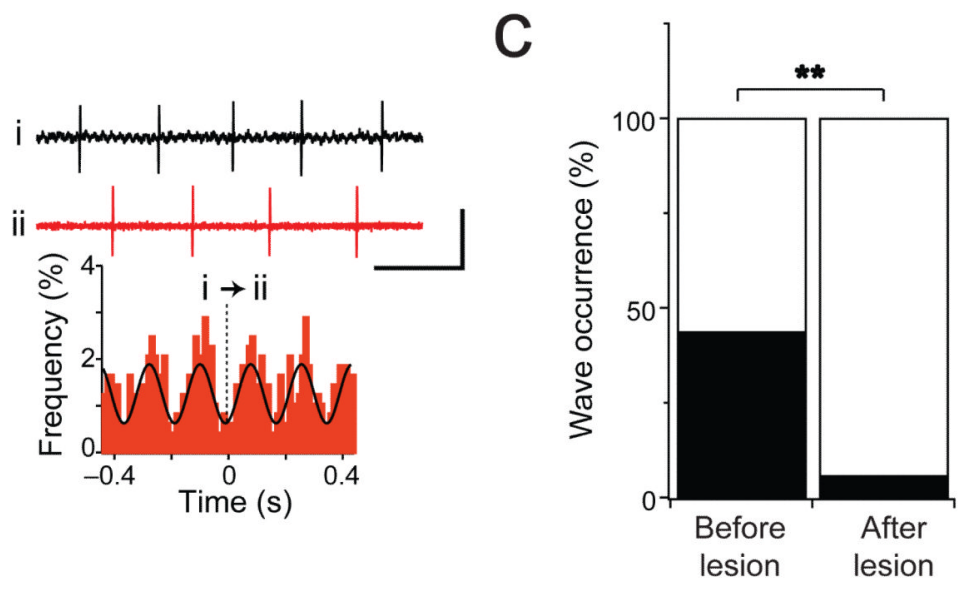

Figure 7. Optical lesion of Purkinje axon collaterals abolishes traveling waves (a) Left: Two-photon image (left) and corresponding laser-scanning Dodt contrast image (middle) of $L 7$-tau-GFPPurkinje cells from a P6 mouse illustrating the recording configuration. Scale bar, $50 \mu \mathrm{m}$. Top right: sample traces from electrodes showing wavelike activity. Scale bars, 200 pA (top trace), 500 pA (bottom trace), 200 ms. Bottom right: Peaks in cross-correlograms indicate firing is correlated.

(b) Images showing same location as in (a) after optical lesioning of collaterals in granule cell layer. The lesion appears both as a bright fluorescent band (left) and a faint scar (middle). Scale bar, $50 \mu \mathrm{m}$. Top right: sample traces from same cells after the optical lesion when wave-like activity is abolished. Scale bars, 500 pA (top trace), 750 pA (bottom trace), $200 \mathrm{~ms}$. Bottom right: Absence of peaks in cross-correlogram after optical lesioning. (c) Waves were seldom observed in Purkinje cells following optical lesioning of axon collaterals. For control data in the same slice, waves were seen at the same rates as previously, $40 \%$ (7 out of 17 recordings). However, across the lesion, waves were seen significantly less often ( 1 out of 18 recordings, $* * \mathrm{P}=0.0047$ ). 

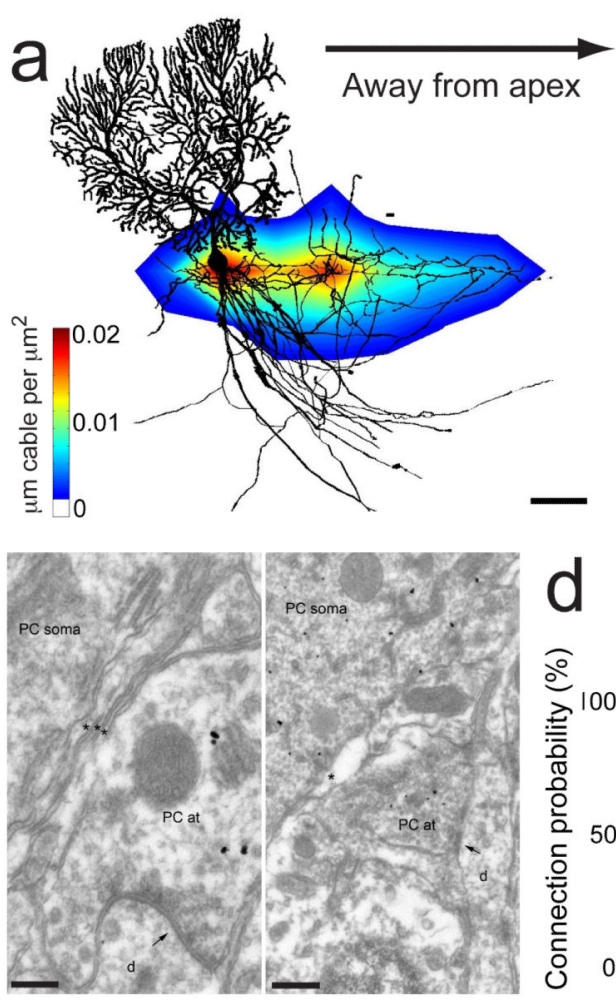

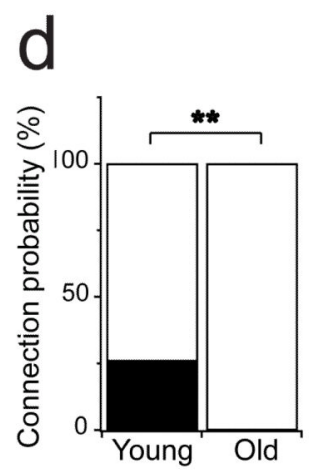

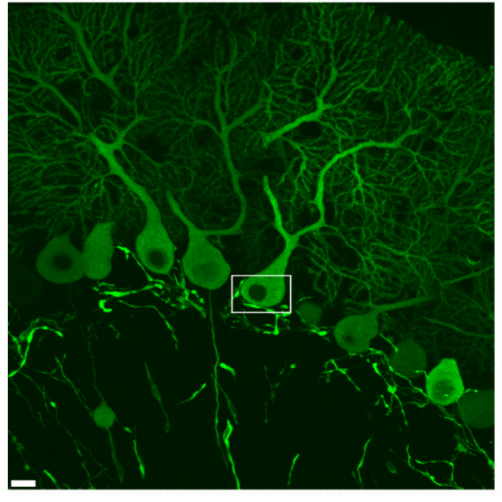
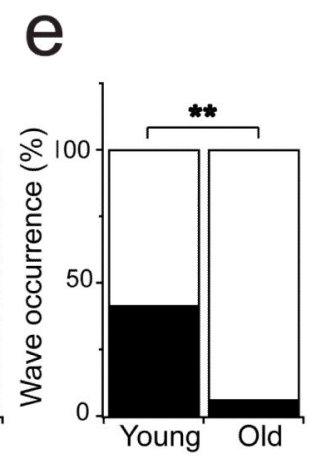
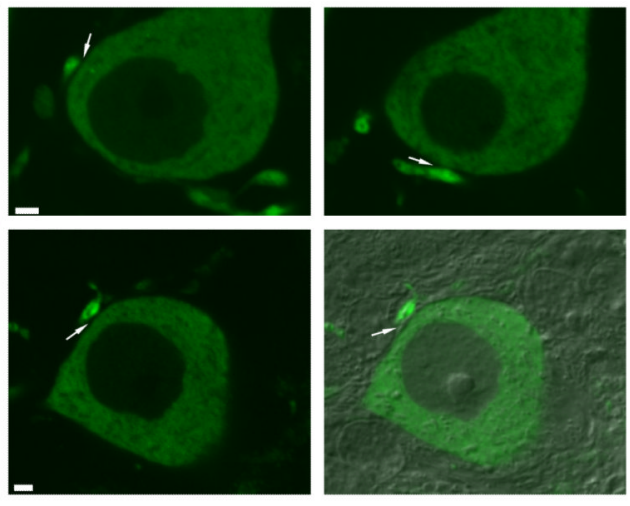

f
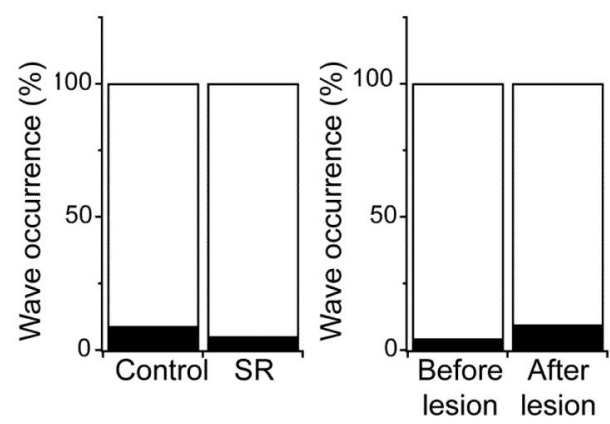

Figure 8. PC-PC connectivity and traveling waves are absent in older animals

(a) Density plot of Purkinje cell axon collaterals from older mice reveals collaterals project asymmetrically away from lobule apex $(n=14$; P17-22; cf. Fig 3b, Methods). Scale bar, 50 $\mu \mathrm{m}$.

(b) Left: confocal image from a P18 mouse. Scale bar, $10 \mu \mathrm{m}$. Right: high-magnification single optical section images from the boxed area in the left panel. Arrows point to gaps between Purkinje cell axon terminals and the soma. Scale bar, $2 \mu \mathrm{m}$.

(c) Electron micrographs showing that Purkinje cell axon terminals ( $\mathrm{PC}$ at) are close to, but do not form synapses with Purkinje cell somata. Often, thin layers of membrane (left; asterisks) or a gap (right; asterisk) separate the structures. Purkinje cell axon terminals establish a synaptic junction (arrows) with unlabelled, non-Purkinje cell dendrite. Scale bars, $0.2 \mu \mathrm{m}$ (left), $0.5 \mu \mathrm{m}$ (right).

(d) The connectivity rate of monosynaptic Purkinje-Purkinje cell connections was significantly reduced in older animals (P4 - P14: 23 in 88 tested connections; P17 - 25: 0 in 25 tested connections; $* * \mathrm{P}<0.001)$.

(e) The occurrence of waves was reduced in older animals, to chance levels (P4 - 6: 17 out of 41 pairs of recordings; $\mathrm{P} 17$ - P25: 5 out of 81 ; ** $\mathrm{P}<0.001)$.

(f) Neither SR95531 (left; matched control: 3 out of 34 pairs of recordings; SR: 1 out of 20 recordings; $\mathrm{P}=0.31$ ) nor optical lesioning of Purkinje cell collaterals (right; before lesion: 2 out of 48 recordings; after lesion: 3 out of 32 recordings; $P=0.18$ ) affect waves in older animals. 


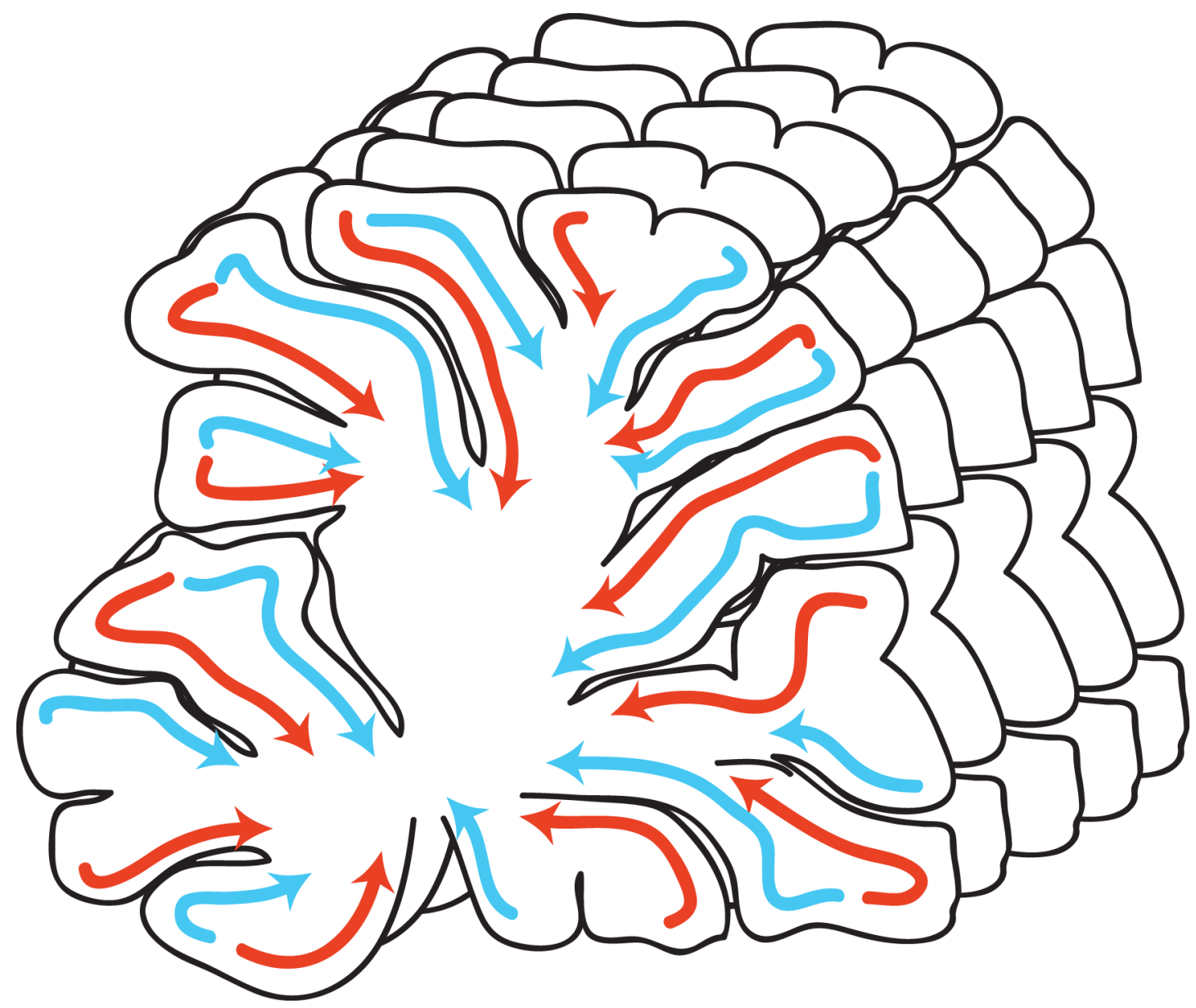

Figure 9. Traveling waves define a novel functional unit in the developing cerebellar cortex A schematic illustration of the functional organization of the juvenile cerebellar cortex described in this study. Purkinje cells form functional units in the sagittal plane defined by their asymmetric collaterals. Thus, in the sagittal plane, each lobule contains two functional units with mirrored symmetry (illustrated here with alternating red and blue arrows). Within each unit, the direction of waves in the lobule depends on developmental stage and on $\mathrm{E}_{\mathrm{GABA}}$. 


\section{Table 1}

\section{Synaptic properties of Purkinje-Purkinje connections}

\begin{tabular}{|l|c|}
\hline & mean \pm s.e.m. [range] \\
\hline peak amplitude of PSP & $1.9 \pm 0.63 \mathrm{mV}[0.3-8.4]$ \\
\hline $20-80 \%$ rise time of PSP & $2.2 \pm 0.24 \mathrm{~ms}[0.7-3.9]$ \\
\hline decay t of PSP & $20 \pm 1.9 \mathrm{~ms}[11-37]$ \\
\hline latency & $0.6 \pm 0.05 \mathrm{~ms}[0.2-0.9]$ \\
\hline CV & $0.9 \pm 0.13[0.4-2.9]$ \\
\hline failure rate & $33 \pm 5 \%[0-78]$ \\
\hline putative synapse number & $3.7 \pm 0.84[2-8]$ \\
\hline $20-80 \%$ rise time of PSC & $0.8 \pm 0.13[0.5-1.6]$ \\
\hline decay $\tau$ of PSC & $5.8 \pm 0.99[1.6-10.6]$ \\
\hline
\end{tabular}

Peak amplitude, rise time, decay $\tau$ and latency values were determined from average PSP ( $n=20$ pairs). Average PSCs were used to determine rise time and decay $\tau$ in voltage clamp recordings $(n=11$ pairs). $C V$ and failure rate were determined from an average of $49 \pm 5$ individual responses. Peak amplitudes include failures; only pairs with symmetrical chloride internal solution were included for peak amplitude measurement $(\mathrm{n}=14)$. To permit accurate measurement of decay $\tau$, we used an amplitude cut-off of $0.4 \mathrm{mV}(\mathrm{n}=17)$. Putative synapse number was determined visually with 100X high numerical aperture objective from fixed biocytin-filled neurons where synaptic connection was confirmed electrophysiologically (n $=7$; see Methods). 